\title{
Intergenerational Mobility in Education and Occupation*
}

\author{
Jaime Alonso-Carrera \\ Universidade de Vigo \\ e-mail: jalonso@uvigo.es \\ Jordi Caballe \\ Universitat Autònoma de Barcelona and Barcelona GSE \\ e-mail: jordi.caballe@uab.es \\ Xavier Raurich \\ Universitat de Barcelona \\ e-mail: xavier.raurich@ub.edu
}

${ }^{*}$ Financial support from the Government of Spain/FEDER through grants ECO2015-66701, ECO2015-67602, and ECO2015-68367; the RecerCaixa program, the French National Research Agency through A*MIDEX project ANR-11-IDEX-0001-02; the Severo Ochoa Program through grant SEV-2015-0563; and the Generalitat of Catalonia through grant 2017-SGR-1765 is gratefully acknowledged. This paper has benefited from comments by participants in the Summer Forum of the Barcelona GSE, ASSET meeting, AMSE workshop in Growth and Development, Navarre-Basque Country Macroeconomics workshop, Madrid Mobility workshop, Regional Science Association meeting, and the Symposium of the Spanish Economic Association. 
Running head:

Mobility in Education and Occupation

Corresponding Author:

Jordi Caballé

Universitat Autònoma de Barcelona.

Departament d'Economia i d'Història Econòmica.

Edifici B.

08193 Bellaterra (Barcelona). Spain.

Phone: (+34)935.812.367

E-mail: jordi.caballe@uab.es 


\begin{abstract}
We build a model that, according to the empirical evidence, gives rise to oscillations in wealth within a dynasty while keeping intergenerational persistence in education attainment. We propose a mechanism based on the interaction between wealth and effort as suggested by the Carnegie conjecture, according to which wealthier individuals devote less effort in their job occupations than poorer. Oscillations in wealth arise from changes in the occupation chosen by different generations of the same dynasty as a response to both inherited wealth and college premium. Our mechanism generates a rich social stratification with several classes in the long run due to the combination of different levels of education and occupation types. Furthermore, we generate a large mobility in wealth among classes even in the long run. Our model highlights the role played by the minimum cost on education investment, the borrowing constraints, and the complementarity between education and occupational effort.
\end{abstract}

Keywords: Intergenerational Mobility, Education, Occupation. 


\section{Introduction}

In this paper, we present a mechanism generating intergenerational mobility and social stratification based on the interaction between wealth, education, and the labor effort associated with different occupations. Our analysis is motivated by three empirical facts. First, there exist empirical support for the so called "Carnegie conjecture", according to which those individuals who receive a large inheritance are tempted to put small effort in productive activities so that they may end up enjoying a small amount of income. ${ }^{1}$ Several empirical papers have documented a negative relationship between labor supply and the amount of inheritance individuals receive. This reduction in the labor supply takes the form of a reduction in the number of hours worked, an early retirement decision, or direct job quitting (see Brown et al., 2010; Cox, 2014; Elinder et al., 2012; Holtz-Eakin et al., 1993; Joulfaian and Wilhelm, 1994, 2006). The size of the negative effect of inheritance in the overall labor income found in these papers is very heterogeneous and depends crucially on both the period of the life cycle where the intergenerational transmission of wealth takes place and the expected or unexpected nature of inheritances (see B $\varnothing$ et al.; 2018, and Kindermann et al., 2017, for the corresponding evidence in Norway and Germany, respectively). We should mention however that there is another channel through which the amount of inheritance could be positively correlated with earnings since it may favor entrepreneurship as it tends to make less binding the liquidity constraints associated with starting a new business and, moreover, the probability of success of that business increases with the amount of initial capital (see Cox, 2014; and Holtz-Eakin, 1994). We will abstract from entrepreneurship decisions in our analysis and restrict our focus on the occupational decision in a regular labor market.

The second empirical fact motivating our analysis is the observed high intergenerational persistence of education especially within highly educated families (see Checchi et al., 1999, and Hertz et al., 2008). In particular, Hertz et al. estimated 
the correlation between years of schooling of fathers and of their children for a large sample of 42 countries. One of the most striking results of their analysis is that the strongest correlations (with values of the correlation coefficient above 0.6) appear in South America (Peru, Ecuador, Panama, Chile, Brazil, Colombia and Nicaragua) and other countries like Egypt, Sri Lanka, and Pakistan where the credit constraints to finance education seem to be quite pervasive. The high persistence in education attainment in South America is also documented in Behrman et al. (2001). However, Nordic countries display lower estimates of intergenerational education correlations (Chevalier et al., 2009 and Hertz et al., 2008), which is consistent with the idea that intergenerational educational persistence is lower in countries with a strong welfare state devoting a large fraction of public spending to education so that borrowing constraints have weaker effects on human capital investment.

Finally, our analysis is also motivated by the empirical evidence suggesting a larger intergenerational persistence in education than in income. This is clearly confirmed in the survey by Blanden (2013), where several studies are combined to provide crosscountry evidence on social mobility in education and in income. More precisely, they provide the coefficient of regression between the years of education of the parents and those of their descendents and between the logarithm of income of the parents and that of their descendents. These coefficients are a well-known measure of social persistence and in the survey both coefficients are available for eight countries. ${ }^{2}$ The average value of the coefficient measuring persistence in income is 0.3 , whereas the average value of the coefficient measuring persistence in education is 0.59 . This large difference allows us to safely conclude that income mobility is substantially larger than mobility in education.

Relying upon the previous empirical evidence, we aim to build a model that gives rise to oscillations in income within a dynasty while keeping intergenerational persistence in education levels. The mechanism that we propose is based on the interaction between wealth and the amount of effort required in the different job occupations as suggested 
by the Carnegie conjecture. In particular, the oscillations in income arise from changes in the types of occupations chosen by different generations as a response to both inherited wealth and education return (or college premium). Moreover, the persistence in education attainment is achieved in our model because only educated individuals will end up leaving an amount of bequest that is large enough to cover the indivisible monetary cost of education faced by their offspring.

Our mechanism generates a rich social stratification with four classes in the long-run: (1) A poor class composed of uneducated individuals who work in occupations requiring a low amount of effort; (2) a rich class composed of educated individuals working in occupations requiring high-effort; (3) a middle class composed of uneducated individuals who work in high-effort occupations; and (4) another middle class composed of educated individuals working in low-effort occupations. ${ }^{3}$ Moreover, we generate large mobility among classes even in the long run. In particular, we obtain both upward and downward mobility and long-run cycles between the two classes of uneducated individuals and between the two classes of educated individuals. These oscillations are in fact a direct consequence of the Carnegie conjecture: when an individual receives a large inheritance he selects a low-effort occupation so that his income decreases. As a consequence, the next generation receives a smaller amount of inheritance, which implies that it will enjoy a lower amount of initial wealth. Their members will then choose an occupation requiring more effort, which increases in turn their income and, thus, the inherited wealth of the family in the next generation. This strong and deterministic mobility in wealth agrees with the studies reported by Cochell and Zeeb (2005), according to which six out of ten affluent families will loose the family fortune by the end of the second generation and nine out of ten will loose it by the end of the third generation. Our model will achieve however a deterministic reversal of fortune in just one generation. This extreme form of mobility will allow us to highlight the key assumptions underlying the mechanism at work. ${ }^{4}$ 
Our theory combines several ingredients. First, we assume that investment in human capital is indivisible so that a minimum level of expenditure on education is required to acquire human capital. Second, we assume that individuals face a borrowing constraint so that only those with a sufficiently high level of initial wealth can afford the cost of education. These two assumptions impose a barrier on human capital investment for poor individuals.

Third, we assume that labor supply is endogenous and indivisible in the sense that individuals have to choose an occupation. We assume that an occupation is the set of productive activities that require a similar amount of effort. Note that the amount of effort associated with an occupation measures several characteristics of the tasks involved in that occupation like, for instance, the amount of stress and responsibility, the degree of physical or psychological wear, or the cost of entry it carries. The intensity in which these characteristics are present in an occupation results in larger disutility for the workers that perform it. Furthermore, to generate a trade off in the occupation choice, we assume that labor earnings are an increasing function of both the human capital level and the amount of disutility that the worker experiences in the occupation he has chosen. As examples of low-effort occupations performed by workers with low education we can mention those of gardeners, waiters, cashiers, salesmen, cleaners or low-rank secretaries. Low-educated workers may chose occupations requiring a high amount of effort like those of firemen, policemen, miners or welders. Examples of occupations requiring relatively small effort performed by high-educated workers are those corresponding to the technical staff of private or public enterprises or to mediumrank executives and public servants. Finally, surgeons, CEOs or judges are examples of highly educated workers who have selected high-effort occupations.

We can thus illustrate the difference in the behavior of intergenerational mobility of earnings and of education by taking into account the observed large intergenerational mobility in occupations inside each educational class. Under the assumption that the 
level of disutility (and thus of earnings) associated with different occupations requiring the same level of education is very heterogeneous, we could attribute the observed large intergenerational mobility in lifetime income to the sizeable differences among the average earnings of different occupations. In this respect, Zylberberg (2013) documents the persistence in the level of education between parents and sons together with a large variability in earnings within each level of education. He reports average annual earnings of occupations with high education requirements of around $\$ 63,000$ with a standard deviation of $\$ 25,000$ and, as he says, "fathers in some well-paid occupations are very likely to have sons in average-salary occupations, without reneging on the long-term perspectives of the dynasty."

Finally, our results rely crucially on the following natural assumption: human capital and the labor effort associated with each occupation are strong complements when determining labor earnings. In other words, the return from exerting effort is higher for the more educated individuals than for the uneducated individuals. This assumption is quite standard in the literature dealing with labor and education (see Aguiar and Hurst, 2007; and Karasiotou, 2012). Moreover, there is empirical evidence suggesting the realism of this assumption. For instance, data from the OECD Labor Force Statistics show that better-educated workers exhibit larger participation rates, retire later, and work more hours.

The main contribution of our model is to show that the existence of a rich social structure with several classes relies both on the differences among wages imposed by technology and on the policies implemented by the government. Thus, non-marginal changes in either wages or fiscal policy may alter the social structure and thus cause dramatic changes in wealth inequality and aggregate output. On the one hand, the changes in the wage distribution occurred in recent years, where we have witnessed an increase in the wage dispersion among different occupations, a rise in the education premium, and a relative decrease of wages in occupations requiring an intermediate 
level of education, have affected indeed the structure of social classes in the economy (see Acemoglu and Autor, 2011; Autor and Dorn, 2013; and Autor et al., 2016). On the other hand, the effect of changes in policy is analyzed in Section 7, where we show that under a strong welfare state that sets a very low cost of education, the class of educated individuals working in occupations requiring a high amount of effort may disappear as the lifetime income net of education cost for the educated will be so high that high-effort occupations will be discouraged according to the Carnegie conjecture. These changes in the existing social classes will affect both inequality and aggregate output. Therefore, the model offers a new framework to study the macroeconomic effects of economic policies, which is based on the interaction between occupational and educational choices.

Our paper is mainly related with that of Degan and Thibault (2016) where the Carnegie conjecture is explicitly modelled. These authors make the amount of effort (and thus of labor income) dependent on the endogenous amount of inheritance individuals receive. The different constellations of parameter values concerning bequest motive and effort cost considered by them give rise to a plethora of patterns of dynamic accumulation of wealth. Our model differs from that of Degan and Thibault because we introduce accumulation of human capital. We therefore contribute to this literature by combining the Carnegie conjecture with an explanation of the persistence in education, which relies on the fact that the acquisition of human capital through education faces a borrowing constraint so that only the individuals who have received a sufficiently large amount of inheritance can afford the indivisible cost of education. Therefore, the bequests left by a parent will play a triple role as they condition the initial wealth of their children, the type of occupation they will choose, and the education level they will acquire through formal education. Both occupation and education will determine in turn the level of lifetime income of the next generation within the dynasty. Galor and Zeira (1993) focus on the educational decision and, therefore, they are able to explain 
the size of the group of educated individuals in the economy. However, they cannot explain the observed important differences across countries in the relative size of high and low-income workers within each education group. ${ }^{5}$ The literature has accounted for these differences within education groups as a result of exogenous innate abilities. In contrast, in our paper, the relative size of high and low-labor income workers within each education group is endogenously explained as a result of the occupational choice. This is an important difference as economic policies change the relative size of both educated workers and of high-wage workers and, hence, our model provides new insights on the effects that economic policies have on inequality and aggregate output.

Our mechanism to generate reversals of fortune within a dynasty does not rely on intergenerational transmission of tastes but only on transmission of both physical wealth and human capital. These two state variables will drive the oscillations in the amounts of occupational effort and bequest across generations in our economy. The models of Doepke and Zilibotti (2008) and Gradstein (2008) assume instead that parents shape the preferences of their children in order to generate wealth oscillations. Doepke and Zilibotti assume that the members of middle-class and poor families develop patience and a work ethic, which are the attitudes that better fit the steepness of the income profile they face in their occupations, whereas the members of upper class families who rely on considerable capital income invest in the appreciation of leisure. Gradstein (2008) proposes a complementary mechanism of intergenerational transmission of preferences where parents have incentives to provide their children with working habits to minimize children dependence on parental transfers. These two mechanisms of endogenous transmission of preferences give also rise to fluctuations of wealth consistent with the Carnegie conjecture.

Our analysis is also related with the literature on the role of borrowing constraints in order to prevent individuals from acquiring education when there is an indivisible cost associated with schooling. As was pointed out by Galor and Zeira (1993), the access 
to education by the poorest individuals depends on whether they can borrow or not. When there are capital market imperfections resulting in borrowing constraints, those individuals with a level of wealth lying below some threshold value cannot afford the cost of education. ${ }^{6}$ Intergenerational transfers from parents to children could help to ameliorate the negative effects of borrowing constraints on the accumulation of human capital. However, in an environment with credit market imperfections, only those individuals who receive a sufficiently large inheritance can invest in human capital (see Becker and Tomes, 1976; Eckstein and Zilcha, 1994; or Behrman et al., 1995). Regarding the dynamics of wealth distribution, Galor and Zeira (1993) show that, if one assumes credit market imperfections and an indivisible cost of education, then the distribution of inherited wealth entirely determines the accumulation of human capital and the dynamics of the subsequent distribution of wealth. Note that in our model each individual will decide how much to invest in her own human capital. Other papers in this strand of literature attribute instead this decision to the parents (Galor and Moav, 2004 and 2006; Alonso-Carrera, et al., 2012).

The paper is organized as follows. Section 2 presents the basic model of intergenerational transmission of wealth and of individual decisions concerning education and occupational choice. Section 3 characterizes the dynamics of bequests. Section 4 and 5 characterize the dynamics of bequest, occupations, and human capital in the short and in the long run, respectively, for the relevant case where education investment is potentially profitable for all individuals. Section 6 analyzes the inequality of wealth in the long run. Section 7 discusses the relationship between the characteristics of the welfare state and social stratification. Section 8 concludes the paper. 


\section{The model}

Let us consider an overlapping-generations economy (OLG) where individuals live for two periods and have offspring at the end of the first period of life. The exogenous number of children per parent is $n>0$, i.e., the gross rate of population growth is $n$. In the first period of his life an individual born in period $t-1$ receives an inheritance $b_{t-1}$ from his parent. This inheritance can be devoted to save the amount $s_{t-1}$ or to pay for education through formal schooling. In the second period of their lives, individuals work, receive a salary $w_{t}$, get a gross return $R_{t}$ per unit of saving, consume the amount $c_{t}$, and leave the amount $b_{t}$ of bequest to each of their offspring. We index a generation by the period at which their members work. Thus, the budget constraints in the two periods of life for an individual belonging to generation $t$ are

$$
b_{t-1}=x_{t-1}+s_{t-1}
$$

and

$$
w_{t}+R_{t} s_{t-1}=c_{t}+n b_{t},
$$

where $x_{t-1}$ is the amount invested in education.

We assume that education has a fixed indivisible cost $\mu$ and impose the typical borrowing constraint on education acquisition so that individuals can only pay for their own education if the amount of inheritance is larger than the fixed cost $\mu$ of education. This borrowing constraint implies that $x_{t-1} \leq b_{t-1}$ or, equivalently, $s_{t-1} \geq 0 .{ }^{7}$

Agents derive utility from the amount consumed in the second period of their lives and from the bequest they leave to each of their descendents. Therefore individuals display a "joy of giving" motivation for bequests (or "warm-glow" altruism) as in Abel (1985) and Yaari (1965). Moreover, we assume that the effort individuals exert in their job occupation results in a loss of utility. We assume the following logarithmic functional form:

$$
U_{t}=\ln c_{t}+\beta \ln b_{t}-\rho e_{t},
$$


where $e_{t}$ is the level of effort, which is assumed to be a discrete variable taking the values 1 for the workers who exert a high amount effort or 0 for the workers who exert a small amount of effort, $e_{t} \in\{0,1\} .^{8}$ As we have also mentioned in the Introduction, we associate the level of effort (or of disutility) with a given occupation so that there are occupations in the economy that require the same level of education but different amount of effort. We are thus assuming for simplicity that there are only two types of occupations for each level of education. Given this assumed discrete nature of effort, the assumption of linear disutility from effort and the normalization to the values 0 and 1 is made without loss of generality.

Individuals live in a small open economy with a constant returns to scale technology. Hence, the gross rate $R_{t}$ of return on capital is exogenously given as it has to be equal to the international rate of return and, thus, since the capital-efficiency units of labor ratio is fully determined by $R_{t}$, the wage rate $\bar{w}_{t}$ per efficiency unit of labor is also given. We assume that both rates are constant along time, $R_{t}=R>0$ and $\bar{w}_{t}=\bar{w}$ for all $t$. The number of efficiency units supplied by a worker born in period $t-1$ depends on both his level of human capital $h_{t}$ and the amount $e_{t}$ of occupational effort he exerts in his occupation according to the strictly positive function $\varepsilon\left(h_{t}, e_{t}\right)$.

We consider a simple form of technological indivisibility in the production of human capital. ${ }^{9}$ In particular, the individual level of capital can take two values depending on whether the investment in education is below or above the fixed indivisible cost $\mu$ of education. Thus, the level of human capital at period $t$ is given by the following function:

$$
h_{t}=\left\{\begin{array}{l}
1 \text { if } x_{t-1} \geq \mu, \\
0 \text { if } x_{t-1}<\mu .
\end{array}\right.
$$

A level of human capital equal to 1 corresponds to educated workers, whereas a level equal to zero corresponds to uneducated workers. Obviously, the optimal investment in education for individuals who cannot afford the minimum cost $\mu$ is $x_{t-1}=0$, whereas 
the individuals who end up being educated are those who choose $x_{t-1}=\mu$. Observe that the individuals who receive an inheritance $b_{t-1}$ strictly smaller than $\mu$ cannot invest in education even if they wish to do so. Therefore, the salary compensation $w_{t}$ of a worker with the level $h_{t}$ of human capital exerting the amount $e_{t}$ of effort in his occupation will be equal to $\varepsilon\left(h_{t}, e_{t}\right) \bar{w}$. Since the wage $\bar{w}$ per efficiency unit is constant, to ease the notation we define the earning function $w\left(h_{t}, e_{t}\right) \equiv \varepsilon\left(h_{t}, e_{t}\right) \bar{w}$ so that

$$
w_{t}=w\left(h_{t}, e_{t}\right)
$$

We assume that the earning function $w\left(h_{t}, e_{t}\right)$ satisfies the following assumption:

\section{Assumption A}

(a) $w\left(h_{t}, 1\right)>w\left(h_{t}, 0\right)$ for all values of $h_{t}$;

(b) $w\left(1, e_{t}\right)>w\left(0, e_{t}\right)$ for all values of $e_{t}$; and

(c) $w(1,1)-w(1,0)>w(0,1)-w(0,0)$

The previous assumption is very plausible. Parts (a) and (b) say that wages are increasing in human capital and occupational effort, while part (c) means that both arguments of the function $w(\cdot, \cdot)$, human capital and occupational effort, are complementary, i.e., the function $w$ is supermodular since to work in a high-effort occupation is more profitable for educated individuals than for uneducated ones. Note that Assumption A does not allow us to make a comparison between the labor income $w(1,0)$ of educated individuals who make little occupational effort and the labor income $w(0,1)$ of non-educated individuals who make large occupational effort. Note that part (c) can be rewritten as

$$
w(1,1)-w(0,1)>w(1,0)-w(0,0)
$$

which means that education is more profitable for the individuals that are willing to work in an occupation requiring a high amount of effort. The complementarity between occupational effort and education implies that a rich individual who can afford the cost 
of education but is not willing to exert high effort may end up not investing in education when the wage premium of education under low occupational effort is small. Similarly, a poor individual who cannot pay for his education may choose a low-effort occupation when the wage premium associated with occupational effort is too low for non-educated individuals.

The problem faced by a generic individual of generation $t$ is to find the values of $c_{t}$, $b_{t}, e_{t}$, and $h_{t}$ in order to maximize (2.3) subject to

$$
w_{t}+R b_{t-1}-R x_{t-1}=c_{t}+n b_{t}
$$

(2.4), $e_{t} \in\{0,1\}$, and $x_{t-1} \leq b_{t-1}$. Note that the constraint (2.7) follows from combining (2.1) and (2.2) and eliminating the saving $s_{t-1}$.

We solve this problem in two steps. First, given the values of education investment $x_{t-1}$ and occupational effort $e_{t}$, we obtain the following optimal values for consumption and bequest:

$$
c_{t}=\frac{w_{t}+R b_{t-1}-R x_{t-1}}{1+\beta}
$$

and

$$
b_{t}=\frac{\beta\left(w_{t}+R b_{t-1}-R x_{t-1}\right)}{n(1+\beta)} .
$$

Next, we evaluate the utility function (2.3) at the optimal level of consumption (2.8) and bequests (2.9), and use (2.5) to obtain the indirect utility

$$
U\left(h_{t}, e_{t}\right)=(1+\beta) \ln \left[w\left(h_{t}, e_{t}\right)-R X\left(h_{t}\right)+R b_{t-1}\right]-\rho e_{t}+M
$$

where $M$ is a constant and $X\left(h_{t}\right)$ is the function mapping human capital into education investment, which is implicitly defined by (2.4),

$$
x_{t-1}=X\left(h_{t}\right)= \begin{cases}\mu & \text { if } h_{t}=1, \\ 0 & \text { if } h_{t}=0 .\end{cases}
$$


Then, we solve for the optimal values of occupational effort and human capital (or, equivalently, of investment in education). Note that the optimal decisions will depend on the inheritance received by individuals. The optimal decisions on education investment and occupation are obtained from the direct comparison between different utility levels. To simplify this comparison we define $\theta \equiv \exp [\rho /(1+\beta)]>1$ so that, using (2.10), we obtain the following implications:

1. The utility of an uneducated agent in a high-effort occupation is larger than the utility of an agent who acquires education but chooses a low-effort occupation if $U_{t}(0,1)>U_{t}(1,0)$, that is, if

$$
\widetilde{b}_{1} \equiv \frac{w(0,1)-\theta[w(1,0)-R \mu]}{(\theta-1) R}>b_{t-1} .
$$

2. Non-educated agents work in a high-effort occupation if $U(0,1)>U(0,0)$, that is, if

$$
\widetilde{b}_{2} \equiv \frac{w(0,1)-\theta w(0,0)}{(\theta-1) R}>b_{t-1}
$$

3. Agents that choose low-effort occupations decide to invest in education if $U(1,0)>U(0,0)$, that is, if

$$
w(1,0)-w(0,0)>R \mu
$$

4. Agents selecting high-effort occupation decide to invest in education if $U(1,1)>U(0,1)$, that is, if

$$
w(1,1)-w(0,1)>R \mu
$$

5. Educated agents choose high-effort occupations if $U(1,1)>U(1,0)$, that is, if

$$
\widetilde{b}_{3} \equiv \frac{w(1,1)-\theta w(1,0)}{(\theta-1) R}+\mu>b_{t-1}
$$


6. The utility of an agent who acquires education and works in high-effort occupations is larger than the utility of an agent who does not invest in education and works in a low-effort occupation if $U_{t}(1,1)>U_{t}(0,0)$, that is, if

$$
\widetilde{b}_{4} \equiv \frac{w(1,1)-\theta w(0,0)-R \mu}{(\theta-1) R}>b_{t-1} .
$$

Implications 1, 2, 5 and 6 highlight the role of the amount of bequests in order to induce workers to choose occupations requiring a high amount of effort. When the amount of inheritance individuals receive is too large, the marginal utility of their consumption and bequest turns out to be small and, thus, they optimally decide not to work in a high-effort occupation as the cost of effort is larger than the potential increase in utility arising from the amounts of own consumption and left bequest. We have thus made explicit the mechanism lying behind the Carnegie conjecture discussed in the Introduction.

To close the characterization of each individual's optimal plan, we should compare the threshold levels of bequests $\widetilde{b}_{1}, \widetilde{b}_{2}, \widetilde{b}_{3}$ and $\widetilde{b}_{4}$. First, we obtain that $\widetilde{b}_{4}>\widetilde{b}_{2}$ and $\widetilde{b}_{3}>\widetilde{b}_{1}$ if and only if

$$
w(1,1)-w(0,1)>R \mu .
$$

Note that the previous condition means that education is profitable for at least those agents who choose high-effort occupations. Second, we obtain that $\widetilde{b}_{4}>\widetilde{b}_{3}$ and $\widetilde{b}_{2}>\widetilde{b}_{1}$ if and only if

$$
w(1,0)-w(0,0)>R \mu .
$$

This condition holds when education is profitable for those agents working in loweffort occupations, which implies that it is also profitable for the agents in high-effort occupations as follows from part (c) of Assumption A. Finally, we obtain that $\widetilde{b}_{3}>\widetilde{b}_{2}$ if and only if

$$
\theta<\widetilde{\theta}_{1} \equiv \frac{w(1,1)-w(0,1)-R \mu}{w(1,0)-w(0,0)-R \mu}
$$


The numerator of (2.14) is the education premium net of education cost for those individuals working in occupations requiring a high amount of effort, whereas the denominator is the net education premium for those who have chosen occupations requiring low effort. Therefore, we have that $\widetilde{b}_{3}>\widetilde{b}_{2}$ when the net labor income gain from education in large-effort occupations is sufficiently large relative to the net labor income gain for the individuals working in low-effort occupations.

\section{The dynamics of bequests}

The characterization of the equilibrium dynamics in this economy depends crucially on part (c) of Assumption A, according to which the effort premium is higher for the educated individuals than for the uneducated ones or, equivalently, the education premium of those agents working in high-effort occupations is larger than the education premium of the individuals working in low-effort occupations (see (2.6)). This assumption is compatible with the following configurations of the parameter values characterizing the wage premia and education cost:

Configuration 1. $R \mu>w(1,1)-w(0,1)$.

Here the capitalized cost of education is larger than the increase in wage due to education for the individuals exerting high occupational effort. Therefore, according to (2.6) education is never profitable and no agent decides to be educated. Since agents never get educated in this scenario, the threshold $\widetilde{b}_{2}$ is the unique relevant threshold. Therefore, agents choose high-effort occupations if $b_{t-1}<\widetilde{b}_{2}$ and choose low-effort occupations if $b_{t-1}>\widetilde{b}_{2}$.

Configuration 2. $w(1,1)-w(0,1)>R \mu>w(1,0)-w(0,0)$.

Here education is profitable only for those agents who exert high occupational effort. It is immediate to see that the thresholds $\widetilde{b}_{1}$ and $\widetilde{b}_{3}$ are not relevant for the dynamics of bequest and, moreover, $\widetilde{b}_{2}<\widetilde{b}_{4}$ in this case. On the one hand, if $\widetilde{b}_{2}<b_{t-1}<\widetilde{b}_{4}$, 
then $U(1,1)>U(0,0)>U(1,0)$ and $U(1,1)>U(0,1)$ for any value of $\widetilde{b}_{1}$ and $\widetilde{b}_{3}$. The previous first inequality follows from the fact that $b_{t-1}<\widetilde{b}_{4}$. The second inequality comes from the fact that education is not profitable for those individuals who make low occupational effort. The third inequality follows from the fact that education is profitable for agents working in high-effort occupations. On the other hand, if $b_{t-1}>\widetilde{b}_{4}$ then $U(0,0)>U(1,1)>U(0,1)$ and $U(0,0)>U(1,0)$ for any value of $\widetilde{b}_{1}$ and $\widetilde{b}_{3}$. The first inequality follows from the fact that $b_{t-1}>\widetilde{b}_{4}$. The second inequality arises from the fact that education is profitable for those individuals who work in high-effort occupations. The third inequality comes from the fact that education is not profitable for agents in low-effort occupations. Therefore, the only relevant inequality for the dynamics of bequest in this scenario is $\widetilde{b}_{2}<\widetilde{b}_{4}$. Finally, under this configuration, we should distinguish between the following two cases:

(a) If $b_{t-1}<\mu$ then agents cannot afford the cost of education. In this case, agents will choose occupations requiring high-effort if $b_{t-1}<\widetilde{b}_{2}$ and will select low-effort occupations if $b_{t-1}>\widetilde{b}_{2}$.

(b) If $b_{t-1}>\mu$ then agents can afford the cost of education. However, they will exert high occupational effort and, thus, they will become educated, if and only if $b_{t-1}<\widetilde{b}_{4}$. Otherwise, they will never acquire education nor exert high effort in their occupations.

Configuration 3. $w(1,0)-w(0,0)>R \mu$.

Here all agents want to invest in education since it is always profitable to become educated regardless of the effort level exerted by workers in their occupations. Under this configuration, the thresholds $\widetilde{b}_{1}$ and $\widetilde{b}_{4}$ are not relevant for the dynamics of bequests because they are respectively smaller and larger than $\widetilde{b}_{3}$. If $b_{t-1}<\widetilde{b}_{3}$, then $U(1,1)>U(1,0)>U(0,0)$ and $U(1,1)>U(0,1)$ for any value of $\widetilde{b}_{1}$ and $\widetilde{b}_{4}$. The first inequality follows from the fact that $b_{t-1}<\widetilde{b}_{3}$, whereas the second and third 
inequalities come from the fact that education is always profitable. On the contrary, if $b_{t-1}>\widetilde{b}_{3}$, then $U(1,0)>U(1,1)>U(0,1)$ and $U(1,0)>U(0,0)$ for any value of $\widetilde{b}_{1}$ and $\widetilde{b}_{4}$. The first inequality follows from the fact that $b_{t-1}>\widetilde{b}_{3}$, whereas the second and third inequalities arise from the fact that education is always profitable. Therefore, the values of $\mu, \widetilde{b}_{2}$ and $\widetilde{b}_{3}$ fully determine the dynamics of bequests. In this scenario, we should distinguish between the same two cases appearing in the previous parameter Configuration 2:

(a) If $b_{t-1}<\mu$ then agents cannot afford the cost of education. In this case, agents make high occupational effort if $b_{t-1}<\widetilde{b}_{2}$ and make small occupational effort if $b_{t-1}>\widetilde{b}_{2}$.

(b) If $b_{t-1}>\mu$ then agents can afford the cost of education. However, they will choose the type of occupation depending on the values of $\widetilde{b}_{3}$.

We will conduct a detailed study of this Configuration 3 in the next section.

For all parameter configurations, we can use (2.9) to write the equilibrium dynamics of bequest as the following difference equation:

$$
b_{t} \equiv B\left(b_{t-1}, h_{t}, e_{t}\right)=\frac{\beta R}{n(1+\beta)}\left[b_{t-1}+\frac{w\left(h_{t}, e_{t}\right)}{R}-X\left(h_{t}\right)\right]
$$

As it is customary in these models, we need a high rate $n$ of population growth, a low rate $R$ of return on saving and a small intergenerational discount factor $\beta$ in order to prevent wealth from growing unboundedly across generations within the same dynasty. The following assumption imposes accordingly the boundedness of the sequence of bequests within a dynasty:

\section{Assumption B}

$$
\lambda \equiv \frac{\beta R}{n(1+\beta)}<1
$$


We can represent the dynamics of bequest in the $\left(b_{t-1}, b_{t}\right)$ space by fixing the values $h_{t}$ of human capital and $e_{t}$ of occupational effort. In this way, we obtain that the dynamics of bequest is characterized by the piecewise linear function $B\left(b_{t-1}, h_{t}, e_{t}\right)$ and the thresholds of inherited bequest $\mu, \widetilde{b}_{2}, \widetilde{b}_{3}$ and $\widetilde{b}_{4}$, which determine in turn the endogenous values of human capital $h_{t}$ and occupational effort $e_{t}$. We will use the following notation: $B^{1}\left(b_{t-1}\right) \equiv B\left(b_{t-1}, 0,0\right), B^{2}\left(b_{t-1}\right) \equiv B\left(b_{t-1}, 0,1\right), B^{3}\left(b_{t-1}\right) \equiv$ $B\left(b_{t-1}, 1,0\right)$ and $B^{4}\left(b_{t-1}\right) \equiv B\left(b_{t-1}, 1,1\right)$. From Assumption A we directly obtain that $B^{3}\left(b_{t-1}\right)<B^{4}\left(b_{t-1}\right)$ and $B^{1}\left(b_{t-1}\right)<B^{2}\left(b_{t-1}\right)$. Moreover, we can obtain the following additional orderings:

(i) $B^{3}\left(b_{t-1}\right)>B^{1}\left(b_{t-1}\right)$ when $w(1,0)-w(0,0)>R \mu$, that is, when education is profitable for all agents regardless of the occupational effort they exert. This is the aforementioned Configuration 3 described above.

(ii) $B^{4}\left(b_{t-1}\right)>B^{2}\left(b_{t-1}\right)$ when $w(1,1)-w(0,1)>R \mu$, that is, when education is profitable for those agents who work in high-effort occupations. This situation can appear when the economy is under the Configurations 2 or 3 described above.

The fixed points of the bequest function (3.1) are the potential steady states for the amount of bequest. These four potential steady states values are given by

$$
\begin{gathered}
b_{1}^{*}=B^{1}\left(b_{1}^{*}\right)=\left(\frac{\lambda}{1-\lambda}\right)\left[\frac{w(0,0)}{R}\right], \\
b_{2}^{*}=B^{2}\left(b_{2}^{*}\right)=\left(\frac{\lambda}{1-\lambda}\right)\left[\frac{w(0,1)}{R}\right], \\
b_{3}^{*}=B^{3}\left(b_{3}^{*}\right)=\left(\frac{\lambda}{1-\lambda}\right)\left[\frac{w(1,0)}{R}-\mu\right],
\end{gathered}
$$

and

$$
b_{4}^{*}=B^{4}\left(b_{4}^{*}\right)=\left(\frac{\lambda}{1-\lambda}\right)\left[\frac{w(1,1)}{R}-\mu\right] .
$$

In the next section we will characterize the transitional dynamics driven by the bequest functions $B^{i}(\cdot), i=1,2,3,4$. We will analyze the evolution of bequest, occupation 
types and human capital when the investment in education is always profitable, which corresponds to the parametric Configuration 3. In the Appendix A we conduct the analysis for the other two configurations.

\section{Transitional dynamics when education is always profitable}

In this section, we characterize the one-period transition of the endogenous variables, inheritance, occupation type, and human capital, across generations when (2.13) holds. Note that, given an initial value of inheritance, individuals choose the optimal values of human capital, occupational effort and bequest left to the descendants and, moreover, the levels of human capital and occupational effort fully determine total individual lifetime income. To conduct a comprehensive analysis, we should consider the three parameter configurations discussed in the previous section. However, since we are interested in an economy where four classes of individuals emerge, namely, educated rich, educated poor, uneducated rich, and uneducated poor individuals, we will restrict our analysis to Configuration 3 in the previous section, which corresponds to a situation where the investment in acquiring human capital is always profitable regardless of the type of occupation individuals choose. On the one hand, under Configuration 1 the cost of education is so high that nobody will acquire education so that no educated individuals will appear in the long-run equilibrium. On the other hand, under the parameter Configuration 2, the class formed by the educated individuals with the smallest earnings (i.e., educated individuals performing low-effort occupations) will not appear in equilibrium since education is only profitable for the individuals willing to exert high effort in their job occupations. Therefore, we are going to assume from now on that $w(1,0)-w(0,0)>R \mu$, which from the supermodularity of the earning function (see part (c) in Assumption A) implies that $w(1,1)-w(0,1)>R \mu$ so that the education premium is always larger than the capitalized value of education cost regardless of the type of occupation. In this case, all the branches of the bequest function (3.1) may 
be operative. Moreover, as it was established in the previous section, we know that $B^{1}\left(b_{t-1}\right)<B^{2}\left(b_{t-1}\right)<B^{4}\left(b_{t-1}\right)$ and $B^{1}\left(b_{t-1}\right)<B^{3}\left(b_{t-1}\right)<B^{4}\left(b_{t-1}\right)$ for all $b_{t-1}$.

Given $b_{t-1}$ individual decisions on bequests, education, and occupational effort will depend on the education cost $\mu$ and the values of the thresholds $\widetilde{b}_{2}$ and $\widetilde{b}_{3}$. Hence, we should distinguish among several cases depending on the ranking among the values of $\mu, \widetilde{b}_{2}$ and $\widetilde{b}_{3}$. We know from the previous section that $\widetilde{b}_{2}<\widetilde{b}_{3}$ if and only if $\theta<\widetilde{\theta}^{1}$ (see (2.14)). We next proceed with the analysis of all these cases:

Case 1. $\mu>\max \left\{\widetilde{b}_{2}, \widetilde{b}_{3}\right\}$.

Here the evolution of bequests, education and occupational effort is given by

$$
\left\{b_{t}, h_{t}, e_{t}\right\}=\left\{\begin{array}{l}
\left\{B^{2}\left(b_{t-1}\right), 0,1\right\} \text { if } b_{t-1}<\widetilde{b}_{2}, \\
\left\{B^{1}\left(b_{t-1}\right), 0,0\right\} \text { if } b_{t-1} \in\left[\widetilde{b}_{2}, \mu\right) \\
\left\{B^{3}\left(b_{t-1}\right), 1,0\right\} \text { if } b_{t-1} \geq \mu .
\end{array}\right.
$$

Observe that the value of the threshold $\widetilde{b}_{3}$ is irrelevant in this case. The dynamics of the variables $b_{t-1}, h_{t}$, and $e_{t}$ is fully governed by the relationship between $\mu, \widetilde{b}_{2}$ and the potential steady states $b_{1}^{*}, b_{2}^{*}$ and $b_{3}^{*}$. Since in this case the number of potential steadystates can be at most three, only three types of individuals (or social classes) may appear in the long run: (i) uneducated agents in high-effort occupations, (ii) uneducated agents in low-effort occupations, and (iii) educated agents in low-effort occupations. Moreover, several stationary dynamics, which involve different social classes in the long run, are possible: we can have locally stable social classes and cycles involving switches between two social classes.

Case 2. $\widetilde{b}_{3}<\mu<\widetilde{b}_{2}$. 
In this case the transition of $b_{t}, h_{t}$, and $e_{t}$ is given by

$$
\left\{b_{t}, h_{t}, e_{t}\right\}=\left\{\begin{array}{l}
\left\{B^{2}\left(b_{t-1}\right), 0,1\right\} \text { if } b_{t-1}<\mu \\
\left\{B^{3}\left(b_{t-1}\right), 1,0\right\} \text { if } b_{t-1} \geq \mu
\end{array}\right.
$$

The relevant dynamics is fully determined by the relationship between $\mu$ and the potential steady states $b_{1}^{*}$ and $b_{2}^{*}$. It is straightforward to see that there will be at most two potential steady states and, hence, only two social classes may appear in the long run: the class of uneducated individuals exerting large occupational effort and the class of educated individuals making little occupational effort.

Case 3. $\widetilde{b}_{2}<\mu<\widetilde{b}_{3}$.

Here the transition of the endogenous variables is given by

$$
\left\{b_{t}, h_{t}, e_{t}\right\}=\left\{\begin{array}{l}
\left\{B^{2}\left(b_{t-1}\right), 0,1\right\} \text { if } b_{t-1}<\widetilde{b}_{2}, \\
\left\{B^{1}\left(b_{t-1}\right), 0,0\right\} \text { if } b_{t-1} \in\left[\widetilde{b}_{2}, \mu\right), \\
\left\{B^{4}\left(b_{t-1}\right), 1,1\right\} \text { if } b_{t-1} \in\left[\mu, \widetilde{b}_{3}\right), \\
\left\{B^{3}\left(b_{t-1}\right), 1,0\right\} \text { if } b_{t-1} \geq \widetilde{b}_{3} .
\end{array}\right.
$$

In the next section we will show that in this scenario the dynamics of the variables $b_{t}, h_{t}$, and $e_{t}$ is fully determined by the relationship between $\mu, \widetilde{b}_{2}, \widetilde{b}_{3}$ and the potential steady states. Note that in this case there are at most four potential stationary values of bequests $b_{1}^{*}, b_{2}^{*}, b_{3}^{*}$ and $b_{4}^{*}$, with $b_{1}^{*}<b_{2}^{*}<b_{4}^{*}$ and $b_{3}^{*}<b_{4}^{*}$. Here many configurations are possible in the long run. For instance, if $\widetilde{b}_{2}<b_{1}^{*}<\mu<b_{2}^{*}<b_{4}^{*}<\widetilde{b}_{3}$ the economy converges towards a two-class society where the two classes correspond to the steady states $b_{1}^{*}$ and $b_{4}^{*}$, with uneducated workers in low-effort occupations and with educated workers in high-effort occupations, respectively. Other configurations are possible like, 
for instance, a two-class society with the classes being locally stable, a three-class society with two classes forming a cycle and the other being locally stable, a single social class constituting a stable stationary equilibrium, a four class-society where two classes form a cycle and the other two form another cycle. The latter case, which could arise under some additional parametric assumptions, will be of special interest for us since it allows the possibility of delivering four social classes in the long run.

Case 4. $\mu<\min \left\{\widetilde{b}_{2}, \widetilde{b}_{3}\right\}$.

In this case the evolution of bequests, education and occupational effort is given by

$$
\left\{b_{t}, h_{t}, e_{t}\right\}=\left\{\begin{array}{l}
\left\{B^{2}\left(b_{t-1}\right), 0,1\right\} \text { if } b_{t-1}<\mu \\
\left\{B^{4}\left(b_{t-1}\right), 1,1\right\} \text { if } b_{t-1} \in\left[\mu, \widetilde{b}_{3}\right), \\
\left\{B^{3}\left(b_{t-1}\right), 1,0\right\} \text { if } b_{t-1} \geq \widetilde{b}_{3} .
\end{array}\right.
$$

Observe that in this case the threshold $\widetilde{b}_{2}$ is irrelevant. Moreover, the relevant dynamics of the endogenous variables is fully determined by the relationship between $\mu, \widetilde{b}_{3}$, and the potential steady states. Since in this case the number of steady states can be at most three, only three classes may appear in the long run: (i) a class with uneducated agents who exert large occupational effort, (ii) a class with educated agents who make little occupational effort, and (iii) a class with educated agents who exert large occupational effort. Several stationary situations are possible in this case: we can have locally stable classes and cycles involving switches between two classes.

\section{The dynamics of dynastic wealth and the existence of cycles}

In this section we will analyze the long-run dynamics of lifetime income and bequests within a given dynasty by using the equilibrium transition of lifetime income and bequests characterized in the previous section. The dynamics of lifetime income 
depends on the return from education (i.e., the education premium), the values of the thresholds of bequest for which individuals switch their decisions concerning the occupation type and the education level, and the values of potential steady states of bequests. We have seen in the previous section that a large number of cases arises for the dynamics of dynastic wealth in spite of the simplicity of our model. In order to comply with the empirical evidence presented in the Introduction, we focus here in a dynamic equilibrium displaying intergenerational persistence in education levels but high intergenerational mobility in wealth. This implies that we should consider those parametric configurations that allow the economy to generate four wealth classes: (i) non-educated individuals in low-effort occupations; (ii) noneducated individuals in high-effort occupations; (iii) educated individuals in loweffort occupations; and (iv) educated individuals in high-effort occupations. Finally, according to our main objective, we will analyze under which conditions the education status is intergenerational preserved while wealth status is not.

From the Case 3 in the previous section, we observe that the previous four-classes scenario occurs only if the two following conditions simultaneously hold :

(a) The education is always profitable regardless the occupation type, $w(1,0)-$ $w(0,0)>R \mu$.

(b) The thresholds of bequests characterizing the bequest function satisfy $\widetilde{b}_{2}<\mu<\widetilde{b}_{3}$.

We now characterize the conditions on the parameters of the model ensuring that $\widetilde{b}_{2}<\mu<\widetilde{b}_{3}$. First, we know that $\widetilde{b}_{2}<\widetilde{b}_{3}$ if and only if $\theta<\widetilde{\theta}^{1}$ (see (2.14)). Secondly, we obtain that $\mu>\widetilde{b}_{2}$ if and only if

$$
\theta>\widetilde{\theta}^{2} \equiv \frac{w(0,1)+R \mu}{w(0,0)+R \mu}
$$

Therefore, the threshold $\widetilde{b}_{2}$ is smaller than the education cost when the utility gain obtained by non-educated individuals from making high occupational effort is 
sufficiently small. To gain some intuition about the previous condition, consider an individual who has received an amount of inheritance equal to the education cost $\mu$ and has decided not to become educated. This marginal individual will prefer not to choose a high-effort occupation if $U(0,0)>U(0,1)$, which using (2.10) becomes

$$
(1+\beta) \ln [w(0,0)+R \mu]+M>(1+\beta) \ln [w(0,1)+R \mu]-\rho+M
$$

After simplifying the previous inequality becomes in turn the condition (5.1). This inequality implies that an individual receiving an amount of inheritance slightly smaller than $\mu$ obviously becomes uneducated and decides to exert low occupational effort. Therefore, he will leave a small bequest to their direct descendants that will not enable them to acquire education. From inspection, we see that inequality (5.1) means that the effort premium in terms of utility for non-educated individuals is small so that the relatively richest uneducated individuals will decide optimally to work in a low-effort occupation. Therefore, the accumulation of wealth within the dynasty will never allow their members to pay for the cost of education. This explains the intergenerational persistence in the low educational levels. Finally, we get that $\widetilde{b}_{3}>\mu$ if and only if

$$
\theta<\widetilde{\theta}^{3} \equiv \frac{w(1,1)}{w(1,0)}
$$

Thus, the threshold $\widetilde{b}_{3}$ is larger than the education cost when the utility gain obtained by educated individuals from making high occupational effort is sufficiently large. Similarly, we can consider an individual who has received an amount of inheritance equal to the education cost $\mu$ and has decided to acquire education This marginal individual will prefer to work in a high-effort occupation if $U(1,1)>U(1,0)$, which using (2.10) becomes

$$
(1+\beta) \ln [w(1,1)]-\rho+M>(1+\beta) \ln [w(1,0)]+M .
$$

After simplifying the previous inequality becomes in turn the condition (5.2). Hence, an individual receiving an amount of inheritance slightly larger than $\mu$ obviously 
becomes educated and decides to work in a high-effort occupation. Therefore, he will leave an amount of bequest to their direct descendants that will enable them to acquire education. Again, from inspection, we see that inequality (5.2) means that the occupational effort premium in terms of utility for educated individuals is large so that the poorest educated individuals will find profitable to perform a high-effort occupation. Hence, the amount of wealth transmitted intergenerationally by means of bequests will be always sufficiently large so as to cover the education cost. This explains the intergenerational persistence in the high educational levels. Therefore, the previous inequalities (5.1) and (5.2) imply the intergenerational segmentation between educated and non-educated individuals. Observe that under the previous conditions the four branches of the bequest function (3.1) are operative (see (4.1)).

The condition $\theta \in\left(\widetilde{\theta}^{2}, \widetilde{\theta}^{3}\right)$ highlights the role of complementarity between education and occupation type in determining the dynamics of wealth as (5.1) and (5.2) imply together a complementarity in terms of utility between education and occupational effort: the premium in terms of utility from working in high-effort occupations is small for non-educated individuals, whereas this premium is large for the educated ones. An economy with four classes does not arise in the absence of complementarity in terms of utility between education and occupational effort. On the one hand, if $\theta<\widetilde{\theta}^{2}$, then the income gain obtained by non-educated individuals from choosing a high-effort occupation is not sufficiently small and, therefore, $\mu<\widetilde{b}_{2}$. We have shown in the previous section that there are three wealth classes at most in this case as the class of uneducated workers performing low-effort occupations does not arise. On the other hand, if $\theta>\widetilde{\theta}^{3}$, then the income gain obtained by educated individuals from making effort is not sufficiently large and, therefore, $\widetilde{b}_{3}<\mu$. We have also shown that there are also three wealth classes at most in this case as there will be no educated individuals working in high-effort occupations. Therefore, the existence of four social classes requires two types of complementarity between education and effort: complementarity 
in terms of labor earnings and complementarity in terms of utility.

As we have said in the previous section, even if the necessary conditions for a fourclass society we have just discussed hold, the economy may exhibit different dynamics depending on the relationship between the thresholds and the potential steady states of bequests. Let us focus our analysis on a particular case where the economy exhibits four classes with very strong persistence of the education status within a dynasty and extreme mobility in wealth within each education type. In fact, this extreme mobility will take the form of a deterministic cycle driven by the forces lying behind the Carnegie conjecture. To this end we need to assume that the bequest function (3.1) does not exhibit any fixed point so that the potential fixed points $b_{1}^{*}, b_{2}^{*}, b_{3}^{*}$, and $b_{4}^{*}$ satisfy the following conditions: $b_{1}^{*}<\widetilde{b}_{2}<b_{2}^{*}$ and $b_{3}^{*}<\widetilde{b}_{3}<b_{4}^{*}$. In Figure 1 we show the bequest function when these conditions hold together with $\theta \in\left(\widetilde{\theta}^{2}, \widetilde{\theta}^{3}\right)$.

\section{[Insert Figure 1]}

We know that $B^{1}\left(b_{t-1}\right)<B^{2}\left(b_{t-1}\right)<B^{4}\left(b_{t-1}\right)$ and $B^{3}\left(b_{t-1}\right)<B^{4}\left(b_{t-1}\right)$ for all $b_{t-1}$. Concerning the relationship between $B^{2}\left(b_{t-1}\right)$ and $B^{3}\left(b_{t-1}\right)$, we know from (3.1) that $B^{2}\left(b_{t-1}\right)<B^{3}\left(b_{t-1}\right)$ if and only if

$$
w(1,0)-R \mu>w(0,1),
$$

that is, when the minimum labor income that can get an educated individual net of education cost is larger than the maximum labor income that can obtain a non-educated individual. Note that from part (c) of Assumption A, condition (5.3) implies that education is always profitable, namely, $w(1,0)-w(0,0)>R \mu$. Therefore, condition (5.3) imposes a stronger profitability condition on education. This is indeed the case depicted in Figure 1. However, we do not need to impose this condition for obtaining the type of dynamics we are looking for.

Figure 2 displays a possible dynamics of bequests for our benchmark economy, where bequests do not converge to any of the potential steady states and the economy 
converges to a four-class society. In the long run, the fraction of educated dynasties will be in a cycle where generations that work in low-effort occupations and leave an amount of bequest equal to $\bar{b}_{4}$ alternate with generations that work in high-effort occupations and leave a bequest equal $\bar{b}_{3}$. The fraction of non-educated dynasties will also be in a cycle where generations that exert small occupational effort and leave an amount of bequest equal to $\bar{b}_{2}$ alternate with generations that make large occupational effort and leave a bequest equal to $\bar{b}_{1}$.

\section{[Insert Figure 2]}

Note that the previous two cycles can also arise even when $B^{2}\left(b_{t-1}\right)>B^{3}\left(b_{t-1}\right)$ as can be seen in the situation depicted in Figure 3.

\section{[Insert Figure 3]}

As was pointed out in the previous section, the dynamics that may emerge under the parametric Case 3 depends crucially on the relationship between $\widetilde{b}_{2}, \widetilde{b}_{3}, \mu$ and the potential steady states of bequest. In fact, the existence of the two cycles illustrated in Figures 2 and 3 requires the following additional restrictions. On the one hand, the cycle governing uneducated dynasties exists if and only if

$$
\bar{b}_{1} \in\left(\widetilde{b}_{2}, \mu\right) \text { and } \bar{b}_{2} \in\left(0, \widetilde{b}_{2}\right)
$$

Clearly, under these conditions, we have $B^{2}\left(\bar{b}_{2}\right)=\bar{b}_{1}$ and $B^{1}\left(\bar{b}_{1}\right)=\bar{b}_{2}$, which guarantees the existence of the cycle followed by non-educated dynasties. Moreover, the cycle followed by educated individuals emerges if and only if

$$
\bar{b}_{3} \in\left(\widetilde{b}_{3}, \infty\right) \text { and } \bar{b}_{4} \in\left(\mu, \widetilde{b}_{3}\right) .
$$

We see that, under the previous conditions, $B^{3}\left(\bar{b}_{3}\right)=\bar{b}_{4}$ and $B^{1}\left(\bar{b}_{4}\right)=\bar{b}_{3}$, which proves the existence of the cycle governing educated dynasties. In Appendix B, the previous two conditions are characterized in terms of the parameter values of the economy. 
Moreover, we show through a numerical example that conditions (5.4) and (5.5) are compatible with the previous conditions (5.1) and (5.2).

Conditions (5.4) and (5.5) have an easy interpretation. On the one hand, the fact that the values of $\bar{b}_{1}$ and $\bar{b}_{2}$ are smaller than the education cost $\mu$ prevents uneducated dynasties from investing in human capital. Therefore, all the dynasties starting with an amount of inheritance smaller than $\mu$ eventually converge to the cycle defined by the pair $\left(\bar{b}_{2}, \bar{b}_{1}\right)$ where generations remain uneducated. On the other hand, all the dynasties with an initial inheritance larger than the education cost $\mu$ will converge to the cycle characterized by the pair $\left(\bar{b}_{4}, \bar{b}_{3}\right)$ where generations remain educated. These latter dynasties enjoy an initial wealth that allows them to purchase education and, moreover, they find very profitable to maintain their education status across generations.

In the Appendix $\mathrm{C}$ we explicitly characterize the previous two long-run cycles under all the aforementioned conditions. On the one hand, the bequests of non-educated individuals oscillate between the following two values:

$$
\bar{b}_{1}=\frac{\lambda[w(0,1)+\lambda w(0,0)]}{\left(1-\lambda^{2}\right) R}
$$

and

$$
\bar{b}_{2}=\frac{\lambda[w(0,0)+\lambda w(0,1)]}{\left(1-\lambda^{2}\right) R} .
$$

The members of generations who inherit the amount $\bar{b}_{1}$ choose low-effort occupations and leave amount $\bar{b}_{2}$ to their descendants, whereas the individuals of the generations inheriting the amount $\bar{b}_{2}$ work in high-effort occupations and leave the amount $\bar{b}_{1}$ as bequest. Observe that $\bar{b}_{2}<\bar{b}_{1}$. On the other hand, the bequests of educated individuals oscillate between the following two values:

$$
\bar{b}_{3}=\frac{\lambda[w(1,1)+\lambda w(1,0)]}{\left(1-\lambda^{2}\right) R}-\frac{\lambda \mu}{1-\lambda}
$$

and

$$
\bar{b}_{4}=\frac{\lambda[w(1,0)+\lambda w(1,1)]}{\left(1-\lambda^{2}\right) R}-\frac{\lambda \mu}{1-\lambda} .
$$


The members of generations inheriting the amount $\bar{b}_{3}$ perform occupations requiring low effort and leave the amount $\bar{b}_{4}$ to their descendants, whereas the individuals of the generations that inherit the amount $\bar{b}_{4}$ choose occupations requiring high-effort and leave the amount $\bar{b}_{3}$. Finally, observe that $\bar{b}_{4}<\bar{b}_{3}$.

Note that our benchmark economy with cycles does not exhibit mobility in human capital in the long-run, whereas it exhibits a very strong mobility in occupation type and, thus, in lifetime income and bequests. The stronger mobility in wealth relative to the mobility in education levels is supported by the empirical evidence as we have argued in the Introduction.

\section{Inequality in the long run and comparative statics}

In this section, we will characterize the long-run inequality emerging in the benchmark economy displaying endogenous cycles. First, we will perform an income comparison between individuals with the same human capital and different occupational effort. Concerning non-educated individuals, we have two types of individuals: (i) individuals who inherit $\bar{b}_{1}$ and work in low-effort occupations (i.e., they receive a large inheritance and a small labor income) so that their lifetime income is given by $R \bar{b}_{1}+w(0,0)$; and (ii) individuals who inherit $\bar{b}_{2}$ and work in occupations requiring a high amount of effort (i.e., they receive a small inheritance and a large labor income) so that their lifetime income is given by $R \bar{b}_{2}+w(0,1)$. Therefore, the income inequality between non-educated individuals is ${ }^{10}$

$$
\left[R \bar{b}_{2}+w(0,1)\right]-\left[R \bar{b}_{1}+w(0,0)\right]=\frac{w(0,1)-w(0,0)}{1+\lambda}>0
$$

With respect to educated individuals, we have two types of individuals: (i) individuals who inherit $\bar{b}_{3}$ and select occupation requiring low effort (i.e., they receive a large inheritance and a small labor income) so that their lifetime income is given by $R \bar{b}_{3}+w(1,0)$; and (ii) individuals who inherit $\bar{b}_{4}$ and work in high-effort occupations 
(i.e., they receive a small inheritance and a large labor income) so that their lifetime income is given by $R \bar{b}_{4}+w(1,1)$. Therefore, the income inequality between noneducated individuals is

$$
\left[R \bar{b}_{4}+w(1,1)\right]-\left[R \bar{b}_{3}+w(1,0)\right]=\frac{w(1,1)-w(1,0)}{1+\lambda}>0 .
$$

We observe that a large inheritance discourages the occupational effort of individuals in the spirit of the Carnegie conjecture. Furthermore, the difference in inheritance is more than compensated by the difference in labor income. Therefore, the educated individuals who receive the larger inheritance will be the poorest among the class of educated individuals. The same applies for the class of non-educated individuals.

We can now compare the income between individuals with different human capital but exerting the same amount of occupational effort. The difference of income between educated and non-educated individuals working in low-effort occupations is

$$
\begin{aligned}
R \bar{b}_{3} & +w(1,0)-\left[R \bar{b}_{1}+w(0,0)\right] \\
& =\frac{\lambda[w(1,1)-w(0,1)]+w(1,0)-w(0,0)}{1-\lambda^{2}}-\frac{\lambda R \mu}{1-\lambda}>0,
\end{aligned}
$$

whereas the difference of income between educated and non-educated workers in higheffort occupations is

$$
\begin{aligned}
R \bar{b}_{4} & +w(1,1)-\left[R \bar{b}_{2}+w(0,1)\right] \\
& =\frac{\lambda[w(1,0)-w(0,0)]+w(1,1)-w(0,1)}{1-\lambda^{2}}-\frac{\lambda R \mu}{1-\lambda}>0 .
\end{aligned}
$$

Obviously, educated individuals exhibit a larger income than non-educated individuals when they devote the same amount of effort in their occupations. This follows from applying to (6.3) and (6.4) the condition $w(1,0)-w(0,0)>R \mu$ and the existence conditions $\bar{b}_{1} \in\left(\widetilde{b}_{2}, \mu\right), \bar{b}_{2} \in\left(0, \widetilde{b}_{2}\right), \bar{b}_{3} \in\left(\widetilde{b}_{3}, \infty\right)$ and $\bar{b}_{4} \in\left(\mu, \widetilde{b}_{3}\right)$.

We can now analyze the effects on the long-run distribution and its associated inequality of marginal variations in the fundamentals of the benchmark economy. Let us start by considering three marginal shocks hitting this economy and their equivalence 
in terms of fiscal policy reforms. For the following analysis we will assume that the government collects taxes on labor and capital income to finance a subsidy to education and a useless government spending. The fiscal revenues or expenses accruing from the changes in taxes or in the subsidy will be accommodated through the corresponding adjustment in the amount of useless government spending and will neither be returned to the individuals nor give rise to changes in other tax figures. These assumptions on fiscal policy imply that marginal policy reforms will have no other economic effect than modifying the wedge between before-tax and the after-tax income from either capital or labor and the wedge between before-subsidy and after-subsidy education cost. As individuals decisions are driven by the after-tax income or the after-subsidy education cost, we conclude that: (i) an increase in the subsidy to education is equivalent to a reduction in the cost of education; (ii) an increase in the labor income taxes is equivalent to a reduction in the education and effort premiums, which are identified by the labor income gaps $w(1,1)-w(1,0), w(0,1)-w(0,0), w(1,1)-w(0,0)$ and $w(1,0)-w(0,1)$; and (iii) an increase in the capital income tax is equivalent to a reduction in the savings return $R$. From expressions (6.1), (6.2), (6.3) and (6.4), it is straightforward to show the following:

1. A marginal reduction in the education cost $\mu$, which is equivalent to an increase in the rate of an education subsidy, results only in an increase in inequality between educated and non-educated individuals. This is so because the individuals who educate their children will have now more disposable income as they have to pay less for education.

2. A reduction in the education and effort premiums implies a decrease in labor income gaps $w(1,1)-w(1,0), w(0,1)-w(0,0), w(1,1)-w(0,0)$ and $w(1,0)-$ $w(0,1)$. As mentioned before, this shock is equivalent to an increase in the labor income taxes. Obviously, this will result in a reduction of inequality between any pair of two classes in this economy. 
3. A marginal decrease in the saving return $R$ is equivalent to a marginal increase in the flat-rate tax on capital income. We see from (6.1), (6.2) and the definition of $\lambda$ in (3.2) that, as $\lambda$ is increasing in $R$, a decrease in the return $R$ results in larger inequality both within the class of educated people and within the class of uneducated people. To understand this effect note that the poorest individuals both within the class of educated and within the class of uneducated have received an inheritance larger than the respective richest individuals. In spite of this larger inheritance they have become poorer because they choose an occupation involving low effort. Therefore, the difference in gross capital income between the richest and the poorest $\left(R\left(\bar{b}_{2}-\bar{b}_{1}\right)\right.$ for the uneducated and $R\left(\bar{b}_{4}-\bar{b}_{3}\right)$ for the educated) increases as the return $R$ becomes lower since $\bar{b}_{2}<\bar{b}_{1}$ and $\bar{b}_{4}<\bar{b}_{3}$. Finally, the comparison concerning the degree of inequality within a class of individuals exerting the same amount of occupational effort is generally ambiguous.

The previous three types of shocks we have just mentioned could alter the social stratification when its introduction is non-marginal. Obviously, a big shock may alter the long-run number of social classes. In the next section, we will analyze the impact of a particular sizeable policy shock affecting the characteristics of the welfare state.

\section{Welfare state and social stratification}

The dynamics of dynastic wealth changes dramatically when some of the conditions generating the previous benchmark economy do not hold. Let us first see what would happen when the relationship between $\widetilde{b}_{2}, \widetilde{b}_{3}, \mu$ and the potential steady states of bequest differs from that of the benchmark economy.

If $\widetilde{b}_{2}<b_{1}^{*}$, then the cycle of non-educated individuals will not emerge. Hence, the non-educated individuals will work in low-effort occupations and will leave a level of bequest equal to $b_{1}^{*}$ in the long run. If $\widetilde{b}_{2}>b_{2}^{*}$, then the cycle of non-educated individuals will not arise. Hence, all the non-educated individuals will choose occupations requiring 
high effort and will leave a level of bequest equal to $b_{2}^{*}$ in the long run. If $\widetilde{b}_{3}<b_{3}^{*}$, then the cycle of educated individuals will not emerge. Hence, the educated individuals will exert high occupational effort and will leave a level of bequest equal to $b_{3}^{*}$ in the long run. Finally, if $\widetilde{b}_{3}>b_{4}^{*}$, then the cycle of educated individuals will not arise. Therefore, all the educated individuals will work in high-effort occupations and will leave a level of bequest equal to $b_{4}^{*}$ in the long run.

From the previous argument, we can conclude that big shocks can lead the benchmark economy to potentially loose some of its four classes. We are now going to illustrate the argument with an example where the education costs is subjected to a sizeable shock. In particular, we are going to assume that a reform in the welfare state is introduced so that the after-subsidy education cost faced by individuals is reduced dramatically. Note that the threshold $\widetilde{b}_{2}$ is independent of the education cost $\mu$ but the threshold $\widetilde{b}_{3}$ decreases by the same amount as the cost $\mu$ does (see (2.11) and (2.12)). Moreover, the value of the fixed point $b_{3}^{*}$ rises as $\mu$ decreases (see 3.5). In Figure 4 we depict the situation emerging after this non-marginal change: the cycle involving educated individuals disappears as $b_{3}^{*}$ has become larger than $\widetilde{b}_{3}$ and, hence, all the educated individuals end up choosing low-effort occupations. This is so because to work in an occupation requiring high-effort is no longer necessary to preserve the education level across individuals belonging to the same dynasty. Moreover, the size of the population that becomes educated increases due to the reduction in $\mu$. This mechanism driving the change in the level of occupational effort exerted by educated individuals complements the one suggested by Prescott (2004), where changes in labor supply were motivated by labor taxes, whereas our mechanism relies directly on the generosity of the welfare state.

\section{[Insert Figure 4]}

Note also that, if the decrease in the education cost is very large, we could arrive at a situation where $\mu<\widetilde{b}_{2}$ and then the cycle of uneducated individuals also disappears 
and there is only one social class in the long run formed by educated individuals working in low-effort occupations as it can be seen in Figure 5 .

\section{[Insert Figure 5]}

A similar analysis leading to the elimination of some social classes can be conducted through sizeable changes in the relative distance between the four wages faced by the potential four classes of our economy. As we have already mentioned, these changes in wages could be a consequence of labor income taxes or of skill-specific technological shocks.

The effects on inequality of the aforementioned big shocks resulting in the elimination of some social classes are obvious as they follow from the measures of inequality considered in Section 6. However, it is important to clarify at this point that those changes in the number and size of social classes have effects on aggregate output that are far from straightforward. In our simple economy, output is just the sum of the total labor income obtained by the different social classes. Thus, aggregate output increases either because the number of educated individuals increases or because the number of individuals in high-effort occupations increases. This double mechanism gives rise to some non-obvious effects of policies on aggregate output. As an example, we have shown that a subsidy to education increases the number of educated individuals but it decreases the number of individuals exerting effort. Therefore, the final effect of this policy on aggregate output is ambiguous and it will depend on the particular parametrization of the economy. Similar conclusions will be obtained if we consider other policies such as the introduction of labor income taxes. We believe that an important insight that emerges from our analysis is that the effects of economic policies on aggregate output are ambiguous when the interaction between educational and occupational decisions is taken into account. This insight implies that the effects of policies can be the opposite in countries that are different either in the parameter values defining their fundamentals or in their initial wealth distributions. 


\section{Conclusions}

In this paper we have characterized the conditions under which an economy could display simultaneously stationary cycles in wealth and persistence in the education attainment across generations. The oscillations of wealth arise because individuals who receive a large inheritance optimally decide to work in occupations generating low disutility, which agrees with the idea underlying the Carnegie conjecture. The resulting lifetime income of these individuals becomes smaller than that of their parents and then they leave a small amount of bequest, which forces the next generation to choose higheffort occupations again. The model displays the realistic feature that uneducated individuals get smaller bequests than educated individuals. This property, together with the existence of a fixed indivisible cost of schooling and a borrowing constraint on education investment, forces the direct descendants of uneducated individuals to remain uneducated. However, the descendants of educated individuals can afford the cost of education thanks to the larger inheritance they receive. Therefore, we obtain a perfect persistence of the education status even tough this persistence is compatible with fluctuations of wealth both inside the class of educated individuals and inside the class of uneducated ones. Our model generates thus a rich social class structure with rich educated workers, poor uneducated workers together with relatively poor educated workers and relatively rich uneducated workers.

Our model is deterministic and all the fluctuations of wealth are endogenous. It is straightforward to generate transitions from each class to any of the other three classes by introducing an exogenous variable, like a class-idiosyncratic productivity shock affecting the relationship between occupation type, human capital, and wage compensation. However, our non-stochastic model allows us to highlight the role that the complementarity between occupational effort and education plays in order to generate this rich class structure exhibiting intergenerational persistence in education levels. When such a complementarity is appropriately modified, the number of classes 
could decrease dramatically and intergenerational mobility in the levels of human capital could arise.

Our analysis provides thus new insights on the factors and policies that either prevent or promote societies characterized by equal opportunity and efficient use of resources. Our model has also obvious implications for economic development as it may explain quite naturally differences in wealth per capita across countries and the existence of poverty traps as a consequence of different education costs, tax systems, or technologies. Moreover, our model directly links the changes in the wage distribution across occupations and the new complementarities among different levels and types of education that technological change has brought about in recent years with the dramatic modification of the social structure (see Autor and Dorn, 2013). 


\section{Appendix}

\section{A. Transitional dynamics when education is not always profitable}

In this appendix we characterize the transition of bequest, occupation type and human capital when the investment in education is either not profitable for all agents or when it is only profitable for the agents working in high-effort occupations. These cases correspond to the parametric Configurations 1 and 2, respectively, which were presented in Section 3.

1. Education is not profitable: $R \mu>w(1,1)-w(0,1)$.

Under this configuration, no individual wants to invest in education because the education premium is always smaller than the present value of education cost with independence of the level of the occupation type. Hence, only the branches $B^{1}\left(b_{t-1}\right)$ and $B^{2}\left(b_{t-1}\right)$ of the bequest function (3.1) are operative, with $B^{1}\left(b_{t-1}\right)<B^{2}\left(b_{t-1}\right)$ for all $b_{t-1}$. Therefore, given $b_{t-1}$ individuals must first decide if they want to work in a high-effort occupation. This decision depends on the value of the threshold $\widetilde{b}_{2}$. Agents work in occupations requiring high effort if $b_{t-1}<\widetilde{b}_{2}$ and in occupations requiring low effort if $b_{t-1}>\widetilde{b}_{2}$. The transition of bequests, education and occupational effort is then given by

$$
\left\{b_{t}, h_{t}, e_{t}\right\}=\left\{\begin{array}{l}
\left\{B^{2}\left(b_{t-1}\right), 0,1\right\} \text { if } b_{t-1}<\widetilde{b}_{2}, \\
\left\{B^{1}\left(b_{t-1}\right), 0,0\right\} \text { if } b_{t-1} \geq \widetilde{b}_{2} .
\end{array}\right.
$$

The dynamics of the endogenous variables is determined by the relationship between $\widetilde{b}_{2}$ and the potential steady states $b_{1}^{*}$ and $b_{2}^{*}$. It is straightforward to see that the following dynamics may arise:

(a) If $\widetilde{b}_{2}>b_{2}^{*}$, then the economy converges to a one-class society with $\left\{b_{t}, x_{t-1}, e_{t}\right\}=\left\{b_{2}^{*}, 0,1\right\}$, i.e., with only uneducated individuals working in high- 
effort occupations.

(b) If $\widetilde{b}_{2}<b_{1}^{*}$, then the economy converges to a one-class society with $\left\{b_{t}, x_{t-1}, e_{t}\right\}=$ $\left\{b_{1}^{*}, 0,0\right\}$, i.e., with only uneducated individuals working in low-effort occupations.

(c) If $\widetilde{b}_{2} \in\left(b_{1}^{*}, b_{2}^{*}\right)$, then the economy does not converge to a steady state. The economy follows instead a cycle. In this case, poor dynasties make large occupational effort and accumulate wealth. When they reach a sufficient large level of bequests, their descendants make little occupational effort and disaccumulate wealth, which makes them poor again. Dynasties eventually converge to a cycle along which poor generations work in high-effort occupations alternate with rich generations work in low-effort occupations. Note that in this case the economy thus converges to a two-class society in the long-run.

2. Education is only profitable for workers who make effort: $w(1,1)-w(0,1)>R \mu>$ $w(1,0)-w(0,0)$.

Here the education premium for workers in occupations requiring high effort is larger than the present value of the education cost. However, this is not the case for the workers in low effort occupations. This implies that the individuals who acquire education should also select a high-effort occupation. Hence, the branch $B^{3}\left(b_{t-1}\right)$ of the bequest function (3.1) is not operative in this scenario. Moreover, under this configuration, we have that $B^{1}\left(b_{t-1}\right)<B^{2}\left(b_{t-1}\right)<B^{4}\left(b_{t-1}\right)$ for all $b_{t-1}$.

Given the amount of inheritance $b_{t-1}$, the individual decision concerning the amount of bequest left, occupation type, and effort depends obviously on the education cost $\mu$ and the values of the thresholds $\widetilde{b}_{2}$ and $\widetilde{b}_{4}$. Hence, we should distinguish between several cases depending on the raking of $\mu, \widetilde{b}_{2}$ and $\widetilde{b}_{4}$. However, we already know from Section 3 that $\widetilde{b}_{2}<\widetilde{b}_{4}$. We next analyze all the possible cases that may arise under this configuration:

Case 1. $\widetilde{b}_{2}<\widetilde{b}_{4}<\mu$. 
Here, the transition of bequests, education and occupational effort is given by

$$
\left\{b_{t}, h_{t}, e_{t}\right\}=\left\{\begin{array}{l}
\left\{B^{2}\left(b_{t-1}\right), 0,1\right\} \text { if } b_{t-1}<\widetilde{b}_{2}, \\
\left\{B^{1}\left(b_{t-1}\right), 0,0\right\} \text { if } b_{t-1} \geq \widetilde{b}_{2}
\end{array}\right.
$$

Observe that in this case the threshold $\widetilde{b}_{4}$ is irrelevant. The dynamics of the endogenous variables is fully driven by the relationship between $\widetilde{b}_{2}$ and the potential steady states $b_{1}^{*}$ and $b_{2}^{*}$. Since in this case the number of steady states can be at most two, the following three configurations may appear in the long run:

(a) If $\widetilde{b}_{2}>b_{2}^{*}$, then the economy converges to a one-class society with $\left\{b_{t}, x_{t-1}, e_{t}\right\}=\left\{b_{2}^{*}, 0,1\right\}$, i.e., with only uneducated individuals working in higheffort occupations.

(b) If $\widetilde{b}_{2}<b_{1}^{*}$, then the economy converges to a one-class society with $\left\{b_{t}, x_{t-1}, e_{t}\right\}=$ $\left\{b_{1}^{*}, 0,0\right\}$, i.e., with only uneducated individuals working in low-effort occupations.

(c) If $\widetilde{b}_{2} \in\left(b_{1}^{*}, b_{2}^{*}\right)$, then the economy does not converge to a steady state. The economy follows instead a cycle. In this case, the poor dynasties make large occupational effort and accumulate wealth and, once they reach a sufficient large level of bequests, their descendants make little occupational effort and disaccumulate wealth, which makes them poor again. Dynasties eventually approach a cycle along which poor generations working in occupations requiring a high amount of effort alternate with rich generations working in low-effort occupations. The economy thus converges to a two-class society in the long-run.

Case 2. $\widetilde{b}_{2}<\mu<\widetilde{b}_{4}$. 
In this case the transition of $b_{t}, h_{t}$, and $e_{t}$

$$
\left\{b_{t}, h_{t}, e_{t}\right\}=\left\{\begin{array}{l}
\left\{B^{2}\left(b_{t-1}\right), 0,1\right\} \text { if } b_{t-1}<\widetilde{b}_{2}, \\
\left\{B^{1}\left(b_{t-1}\right), 0,0\right\} \text { if either } b_{t-1} \in\left[\widetilde{b}_{2}, \mu\right) \text { or } b_{t-1} \geq \widetilde{b}_{4}, \\
\left\{B^{4}\left(b_{t-1}\right), 1,1\right\} \text { if } b_{t-1} \in\left[\mu, \widetilde{b}_{4}\right) .
\end{array}\right.
$$

The dynamics of bequest and lifetime income is then fully determined by the relationship between the bequest threshold $\widetilde{b}_{2}$ and the potential steady states $b_{1}^{*}$ and $b_{2}^{*}$, and the relationship between the bequest threshold $\widetilde{b}_{4}$ and the potential steady states $b_{3}^{*}$ and $b_{4}^{*}$. Since in this case the number of steady states can be at most three, only three classes may appear in the long run: (i) the class of uneducated who exert large occupational effort, (ii) the class of uneducated who make little occupational effort, and (iii) the class of educated who exert large occupational effort. Several stationary dynamics are possible: we can have locally stable classes and cycles involving switches between two classes.

Case 3. $\mu<\widetilde{b}_{2}<\widetilde{b}_{4}$.

In this case the transition of bequests, education and occupational effort is given by

$$
\left\{b_{t}, h_{t}, e_{t}\right\}=\left\{\begin{array}{l}
\left\{B^{2}\left(b_{t-1}\right), 0,1\right\} \text { if } b_{t-1}<\mu \\
\left\{B^{4}\left(b_{t-1}\right), 1,1\right\} \text { if } b_{t-1} \in\left[\mu, \widetilde{b}_{4}\right) \\
\left\{B^{1}\left(b_{t-1}\right), 0,0\right\} \text { if } b_{t-1} \geq \widetilde{b}_{4} .
\end{array}\right.
$$

Observe that in this case the value of the threshold $\widetilde{b}_{2}$ is irrelevant. The dynamics of bequest and lifetime income is then fully determined by the relationship between the education cost $\mu$, the bequest threshold $\widetilde{b}_{4}$, and the three potential steady states of bequests $\left(b_{1}^{*}, b_{2}^{*}\right.$ and $\left.b_{4}^{*}\right)$. As in the previous case, since the number of steady states 
can be at most three, only three classes may appear in the long run: (i) the class of uneducated individuals working in occupation requiring a high amount of effort, (ii) the class of uneducated workers who make little occupational effort, and (iii) the class of educated individuals working in a high-effort occupations. Similarly, several stationary dynamics are possible: we can have locally stable classes and cycles involving switches between two classes.

\section{B. Conditions for the existence of two cycles}

Using (2.11), (5.6) and (5.7), conditions (5.4) for the existence of the cycle governing non-educated families can be written as

$$
\begin{gathered}
{\left[\lambda(\theta-1)-\left(1-\lambda^{2}\right)\right] w(0,1)+\left(\theta-\lambda^{2}\right) w(0,0)>0,} \\
\lambda[w(0,1)+\lambda w(0,0)]<\left(1-\lambda^{2}\right) R \mu
\end{gathered}
$$

and

$$
\left(\lambda^{2} \theta-1\right) w(0,1)+\left[\lambda(\theta-1)+\theta\left(1-\lambda^{2}\right)\right] w(0,0)<0
$$

Similarly, using (2.12), (5.8) and (5.9), conditions (5.5) for the emergence of the cycle followed by educated individuals become

$$
\begin{gathered}
{\left[\lambda(\theta-1)-\left(1-\lambda^{2}\right)\right] w(1,1)+\left(\theta-\lambda^{2}\right) w(1,0)>(\theta-1)(1+\lambda) R \mu} \\
\lambda[w(1,0)+\lambda w(1,1)]>(1+\lambda) R \mu
\end{gathered}
$$

and

$$
\left(\lambda^{2} \theta-1\right) w(1,1)+\left[\lambda(\theta-1)+\theta\left(1-\lambda^{2}\right)\right] w(1,0)<(\theta-1)(1+\lambda) R \mu .
$$

Solving for $\theta$ in inequality (B.1), we see that this inequality holds if and only if $\theta>\underline{\theta}_{2}$, where

$$
\underline{\theta}_{2} \equiv \frac{\left(1+\lambda-\lambda^{2}\right) w(0,1)+\lambda^{2} w(0,0)}{\lambda w(0,1)+w(0,0)}
$$


Inequality (B.2) can be expressed as a constraint on the maximum value of $\lambda$. To see this, we rewrite the inequality as the following second order polynomial inequality in the slope $\lambda$ of the bequest function:

$$
P(\lambda) \equiv \lambda^{2}(w(0,0)+R \mu)+\lambda w(0,1)-R \mu<0 .
$$

Note that the unique positive solution for $P(\lambda)=0$ is

$$
\bar{\lambda}=\frac{-w(0,1)+\sqrt{w(0,1)^{2}+4[w(0,0)+R \mu] R \mu}}{2(w(0,0)+R \mu)} .
$$

so that (B.2) holds if and only if $\lambda<\bar{\lambda}$.

Solving for $\theta$ in inequality (B.3), we see that this inequality holds if and only if $\theta<\bar{\theta}_{1}$, where

$$
\bar{\theta}_{1} \equiv \frac{w(0,1)+\lambda w(0,0)}{\lambda^{2} w(0,1)+\left(1+\lambda-\lambda^{2}\right) w(0,0)} .
$$

If we solve for $\theta$ in inequality (B.4), we get that this inequality can be written as $\theta>\underline{\theta}_{1}$, where

$$
\underline{\theta}_{1} \equiv \frac{\left(1+\lambda-\lambda^{2}\right) w(1,1)+\lambda^{2} w(1,0)-(1+\lambda) R \mu}{\lambda w(1,1)+w(1,0)-(1+\lambda) R \mu} .
$$

Note that the denominator of the previous expression is positive since $w(1,1)>$ $w(1,0)>R \mu$ under the Configuration 3 we are considering.

Similarly, inequality (B.5) can be expressed as a constraint on the minimum value of $\lambda$. To see this, we rewrite the inequality as the following second order polynomial inequality in the slope $\lambda$ of the bequest function:

$$
Q(\lambda) \equiv \lambda^{2} w(1,1)+\lambda[w(1,0)-R \mu]-R \mu>0 .
$$

The unique positive solution for $Q(\lambda)=0$ is

$$
\underline{\lambda}=\frac{-[w(1,0)-R \mu]+\sqrt{[w(1,0)-R \mu]^{2}+4 w(1,1) R \mu}}{2 w(1,1)} .
$$

so that (B.5) holds whenever $\lambda>\underline{\lambda}$. 
Finally, inequality (B.6) holds if and only if

$$
\theta<\bar{\theta}_{2} \equiv \frac{w(1,1)+\lambda w(1,0)-(1+\lambda) R \mu}{\lambda^{2}[w(1,1)-w(1,0)]+(1+\lambda)[w(1,0)-R \mu]}
$$

where the denominator of $\bar{\theta}_{2}$ is positive.

Therefore, we can summarize our previous analysis by saying that conditions (5.4) and (5.5) for the existence of two cycles are equivalent to the following:

$$
\lambda \in(\underline{\lambda}, \bar{\lambda}) \quad \text { and } \quad \theta \in\left(\max \left\{\underline{\theta}_{1}, \underline{\theta}_{2}\right\}, \min \left\{\bar{\theta}_{1}, \bar{\theta}_{2}\right\}\right)
$$

We next provide an example under which all the conditions that give rise to the existence of two cycles with extreme intergenerational mobility in the amount of inheritance and absolute persistence in education levels are satisfied. Consider thus the following values for the four wages of the economy:

$$
w(0,0)=0.5, \quad w(0,1)=1.15, \quad w(1,0)=2.5, \quad w(1,1)=5 .
$$

We choose the values of $\mu, R, n$, and $\beta$ so that $\lambda=0.17, R \mu=0.3$ and $\theta=1.91$. Under this parameter configuration, we get that $\underline{\lambda}=0.109$ and $\bar{\lambda}=0.225$, so that $\lambda \in(\underline{\lambda}, \bar{\lambda})$. Moreover, in this case we get $\bar{\theta}_{1}=2.0454, \bar{\theta}_{2}=1.9174, \underline{\theta}_{1}=1.809, \underline{\theta}_{2}=1.9076$ so that $\theta \in\left(\max \left\{\underline{\theta}_{1}, \underline{\theta}_{2}\right\}, \min \left\{\bar{\theta}_{1}, \bar{\theta}_{2}\right\}\right)$.

Note that this example satisfies the condition under which education is always profitable for all individuals since $w(1,0)-w(0,0)=2>R \mu=0.3$. Finally, the conditions (5.1),

$$
\frac{w(0,1)+R \mu}{w(0,0)+R \mu}=1.81<\theta=1.91
$$

and

$$
\frac{w(1,1)}{w(1,0)}=2>\theta=1.91
$$

are also satisfied. 


\section{Characterization of cycles in the benchmark economy}

Next, we explicitly find the two cycles that arise in the Benchmark Economy.

(a) We will first characterize the cycle that emerges for non-educated individuals. To this end we use Figure 6 . The cycle implies that those dynasties with a initial bequest below the education cost $\mu$ converge to a cycle along which their bequests oscillate between two social classes characterized by the bequest values $B^{1}\left(b_{t-1}\right)$ and $B^{2}\left(b_{t-1}\right)$. More precisely, they oscillate between point $A$ and $C$ in Figure 6 . Observe that the point $A$ corresponds to $\left\{b_{t}, h_{t}, e_{t}\right\}=\left\{\bar{b}_{2}, 0,1\right\}$, whereas point $C$ corresponds to $\left\{b_{t}, h_{t}, e_{t}\right\}=\left\{\bar{b}_{1}, 0,0\right\}$. In order to compute the bequest levels $\bar{b}_{1}$ and $\bar{b}_{2}$, we use the fact that the cycle defines the square $\overline{A B C D}$. Hence, the following conditions should hold in a cycle:

$$
\bar{b}_{1}-\left(\lambda \bar{b}_{1}+a\right)=\bar{b}_{1}-\bar{b}_{2},
$$

and

$$
\bar{b}_{2}-\left(\lambda \bar{b}_{2}+c\right)=\bar{b}_{2}-\bar{b}_{1}
$$

with

$$
a=\frac{\lambda w(0,0)}{R}
$$

and

$$
c=\frac{\lambda w(0,1)}{R}
$$

By solving the system (C.1)-(C.2), we obtain

$$
\bar{b}_{1}=\frac{\lambda a+c}{1-\lambda^{2}},
$$

and

$$
\bar{b}_{2}=\frac{\lambda c+a}{1-\lambda^{2}}
$$

which become equal to the expressions (5.6) and (5.7), respectively. In order to prove the existence of this cycle, we should ensure that $\bar{b}_{1}$ and $\bar{b}_{2}$ are in the 
operative part of policy functions $B^{1}\left(b_{t-1}\right)$ and $B^{2}\left(b_{t-1}\right)$, respectively. From Figures 2 or 3 we see that this hold in the benchmark economy when $\bar{b}_{2} \in\left(0, \widetilde{b}_{2}\right)$ and $\bar{b}_{1} \in\left(\widetilde{b}_{2}, \mu\right)$.

\section{[Insert Figure 6]}

(b) Using the same procedure as before we characterize the cycle that emerges for the educated individuals. The existence of a cycle implies that those dynasties with a initial bequest above $\mu$ converge to a cycle of two social classes along which their bequests oscillate between $B^{3}\left(b_{t-1}\right)$ and $B^{4}\left(b_{t-1}\right)$. More precisely, they oscillate between two points: $\left\{b_{t}, h_{t}, e_{t}\right\}=\left\{\bar{b}_{3}, 1,0\right\}$ and $\left\{b_{t}, h_{t}, e_{t}\right\}=\left\{\bar{b}_{4}, 1,1\right\}$, with

$$
\bar{b}_{3}=\frac{\lambda m+n}{1-\lambda^{2}}
$$

and

$$
\bar{b}_{4}=\frac{\lambda n+m}{1-\lambda^{2}},
$$

where

$$
m=\lambda\left[\frac{w(1,0)}{R}-\mu\right]
$$

and

$$
n=\lambda\left[\frac{w(1,1)}{R}-\mu\right]
$$

After some algebra, (C.1) and (C.2) become equal to (5.8) and (5.9), respectively. This cycle exist if $\bar{b}_{3}$ and $\bar{b}_{4}$ are in the operative part of policy functions $B^{3}\left(b_{t-1}\right)$ and $B^{4}\left(b_{t-1}\right)$, respectively. By using Figures 2 or 3 , we see that this happens in the benchmark economy when $\bar{b}_{3} \in\left(\widetilde{b}_{3}, \infty\right)$ and $\bar{b}_{4} \in\left(\mu, \widetilde{b}_{3}\right)$. 


\section{Notes}

${ }^{1}$ Andrew Carnegie, the famous 19th century steel businessman, stated: "the parent who leaves his son enormous wealth generally deadens the talents and energies of the son, and tempts him to live a less useful and less worthy life than he otherwise would ..." (Carnegie, 1962).

${ }^{2}$ The countries for which both coefficients are available are Brazil, United States of America, United Kingdom, Italy Norway, Sweden, Finland and Denmark.

${ }^{3}$ We show that our mechanism generates different patterns of social stratification involving a smaller number of social classes. However, we focus our analysis in the four classes' society because it offers a more complete characterization of the economy. In fact, the four classes' society is the only one that can explain the observed income differences within each education group.

${ }^{4}$ Popular tradition in most cultures handles proverbs that casually account for the existence of the Carnegie effect. For example, an English proverb says "clogs to clogs in three generations". Similar examples can be found in Chinese, American, Japanese, Spanish or Italian cultures.

${ }^{5}$ In Alonso-Carrera, et al. (2016) we use data from the EU-Statistics on Income and Living Conditions (SILC) 2004-14 to show that there are large cross-country differences concerning the relative sizes of high and low-income individuals within each education group.

${ }^{6}$ Dynarski (2002) and Keane (2002) analyze empirically the effect of borrowing constraints on decisions concerning human capital acquisition.

${ }^{7}$ The model could be reformulated along the lines of Alonso-Carrera et. al. (2012), 
Galor and Moav (2004 and 2006), or Zilcha (2003) in order to allow parents to pay directly for the education of their children.

${ }^{8}$ Effort is a characteristic of an occupation and, given that the number of occupations is discrete, effort is also a discrete variable in this paper.

${ }^{9}$ Production of human capital takes places through formal education. Therefore, workers become educated and able to obtain the wage corresponding to educated workers only after finishing their studies. This justifies the technological indivisibility in the production of human capital.

${ }^{10}$ The measure of inequality in this section is a measure of polarization between the income of different groups. Other measures of inequality, like the Gini index, will depend on the size of the different groups. As the size depends on the initial distribution of bequest, we would not be able to obtain general conclusions if we had used the Gini index as a measure of inequality. 


\section{References}

Abel, Andrew B. (1985) Precautionary Saving and Accidental Bequests. American Economic Review 75, 777-791.

Acemoglu, Daron and David H. Autor (2011) Skills, Tasks and Technologies: Implications for Employment and Earnings. In Orley Ashenfelter and David Card (eds.), Handbook of Labor Economics, vol. 4, part B, pp. 1043-1171. Amsterdam: Elsevier.

Aguiar, Mark and Erik Hurst (2007) Measuring Trends in Leisure: The Allocation of Time Over Five Decades. Quarterly Journal of Economics 122, 969-1006.

Alonso-Carrera, Jaime, Jordi Caballé, and Xavier Raurich (2012) Fiscal Policy, Composition of Intergenerational Transfers. Journal of Economic Behavior and Organization 84, 62-84.

Alonso-Carrera, Jaime, Jordi Caballé, and Xavier Raurich (2016) Intergenerational Mobility, Occupational Decision and the Distribution of Wages. Barcelona GSE Working Papers Series 945.

Autor, David. H. and David Dorn (2013) The Growth of Low-Skill Service Jobs and the Polarization of the US Labor Market. American Economic Review 103, 1553-1597.

Autor, David. H., Lawrence F. Katz, and Melissa S. Kearney (2006) The Polarization of the U.S. Labor Market. American Economic Review 96, 189-194.

Becker, Gary S. and Nigel Tomes (1986) Human Capital and the Rise and Fall of Families. Journal of Labor Economics 4, S1-S38.

Behrman, Jere R., Robert A. Pollak, and Paul Taubman (1995) The Wealth Model: Efficiency in Education and Distribution in the family. In Jere R. Behrman, Robert A. Pollak, and Paul Taubman (eds.), From Parent to Child: Intra-household Allocations 
and Intergenerational Relations in the United States, pp. 138-182. Chicago: University of Chicago Press.

Behrman Jere R., Alejandro Gaviria, Miguel Székely, Nancy Birdsall, and Sebastián Galiani (2001) Intergenerational Mobility in Latin America. Economía 2, 1-44.

Bø, Erlend E., Elin Halvorsen, and Thor O. Thoresen (in press) Heterogeneity of the Carnegie Effect. Journal of Human Resources.

Blanden, Jo, (2013) Cross-Country Rankings in Intergenerational Mobility: a Comparison of Approaches from Economics and Sociology. Journal of Economic Surveys 27, 38-73.

Brown, Jeffrey R., Courtney C. Coile, and Scott J Weisbenner (2010) The Effect of Inheritance Receipt on Retirement. Review of Economics and Statistics 92, 425-434.

Carnegie, Andrew (1962) The Gospel of Wealth and other Timely Essays. Cambridge, MA: Harvard University Press.

Checchi, Daniele, Andrea Ichino, and Aldo Rustichini (1999) More Equal but less Mobile? Education Financing and Intergenerational Mobility in Italy and in the US. Journal of Public Economics 74, 351-393.

Chevalier, Arnaud, Kevin Denny, and Dorren McMahon (2009) A Multi-country Study of Inter-generational Educational Mobility". In: Peter Dolton, Rita Asplund, and Erling Barth (eds.), Education and Inequality Across Europe. Cheltenham, UK, and Northampton, USA: Edward Elgar.

Cochell, Perry L. and Rodney C. Zeeb (2005) Beating the Midas Curse. Portland, OR: Heritage Institute Press.

Cox, Donald (2014) Inheritance, Bequests, and Labor Supply, IZA World of Labor.

Degan, Arianna and Emmanuel Thibault (2016) Dynastic Accumulation of Wealth. Mathematical Social Sciences 81C, 66-78. 
Doepke, Matthias and Fabrizio Zilibotti (2008) Occupational Choice and the Spirit of Capitalism. Quarterly Journal of Economics 123, 747-793

Dynarski, Susan (2002) The Behavioural and Distributional Implications of Aid for College. American Economic Review (Papers and Proceedings) 92, 279-285.

Eckstein, Zvi and Itzhak Zilcha (1994) The Effects of Compulsory Schooling on Growth, Income Distribution and Welfare. Journal of Public Economics 54, 339-359.

Elinder, Mikael, Oscar Erixson, and Henry Ohlsson (2012) The Impact of Inheritances on Heirs' Labor and Capital Income. B.E. Journal of Economic Analysis and Policy $12,1-35$.

Galor, Oded and Omer Moav (2004) From Physical to Human Capital Accumulation: Inequality and the Process of Development. Review of Economic Studies 71, 1001-1026. Galor, Oded and Omer Moav (2006) Das Human-Kapital: a Theory of the Demise of the Class-structure. Review of Economic Studies 73, 85-117.

Galor, Oded and Joseph Zeira (1993) Income Distribution and Macroeconomics. Review of Economic Studies 60, 35-52.

Gradstein, Mark (2008) Endogenous Reversals of Fortune. IZA Discussion Paper 469. Hertz, Tom, Tamara Jayasundera, Patrizio Piraino, Sibel Selcuk, Nicole Smith, and Alina Verashchagina (2008) The Inheritance of Educational Inequality: International Comparisons and Fifty-year Trends. The B.E. Journal of Economic Analysis and Policy 7, Article 10.

Holtz-Eakin, Douglas, David Joulfaian, and Harvey S. Rosen (1993) The Carnegie Conjecture: Some Empirical Evidence. Quarterly Journal of Economics 108, 413-435. Holtz-Eakin, Douglas, David Joulfaian, and Harvey S. Rosen (1994) Entrepreneurial Decisions and Liquidity Constraints. The RAND Journal of Economics 25, 334-347. 
Joulfaian, David and Mark O. Wilhelm (1994) Inheritance and Labor Supply. Journal of Human Resources 29, 1205-1234.

Joulfaian, David and Mark O. Wilhelm (2006) Inheritance and Saving. NBER Working Paper 12569.

Karasiotou, Pavlina (2012) Education and the Labor Market. Reflets et Perspectives de la Vie Économique 51, 51-72.

Keane, Michael P. (2002) Financial Aid, Borrowing Constraints, and College Attendance: Evidence from Structural Estimates. American Economic Review (Papers and Proceedings) 92, 293-297.

Kindermann, Fabian, Lukas Mayr, and Dominik Sachs (2017) Inheritance Taxation and Wealth Effects on the Labor Supply of Heirs. Manuscript.

Prescott, Edward C. (2004) Why Do Americans Work So Much More Than Europeans? Federal Reserve of Minneapolis Quarterly Review, 28, 2-13.

Yaari, Menahem E. (1965) Uncertain Lifetime, Life Insurance, and the Theory of the Consumer. Review of Economic Studies 32, 137-150.

Zilcha, I., (2003) Intergenerational transfers, production and income distribution. Journal of Public Economics 87, 489-513.

Zylberberg, Y., (2013) Dynastic Income Mobility. Manuscript. 


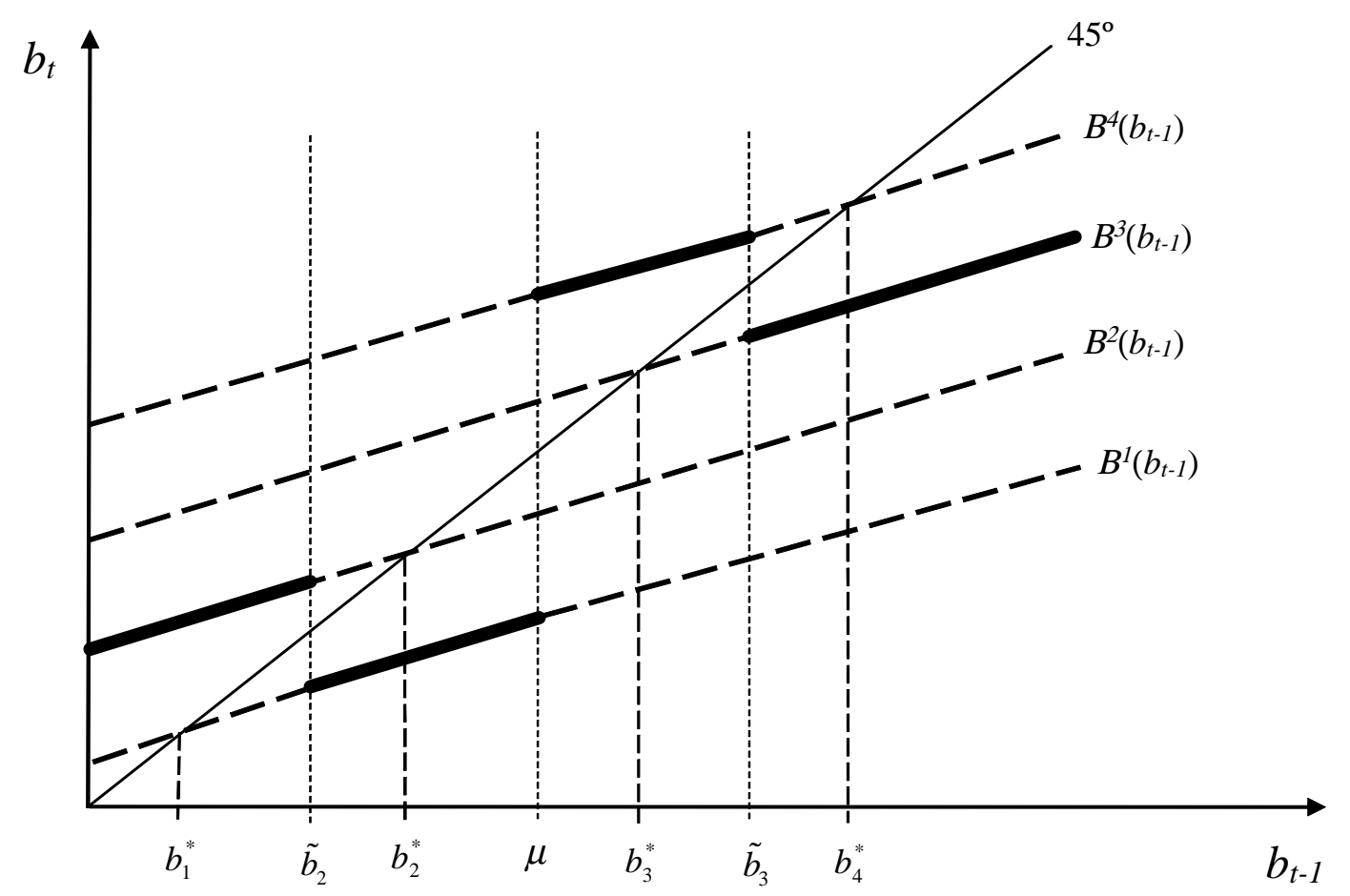

Figure 1. The bequest function. 


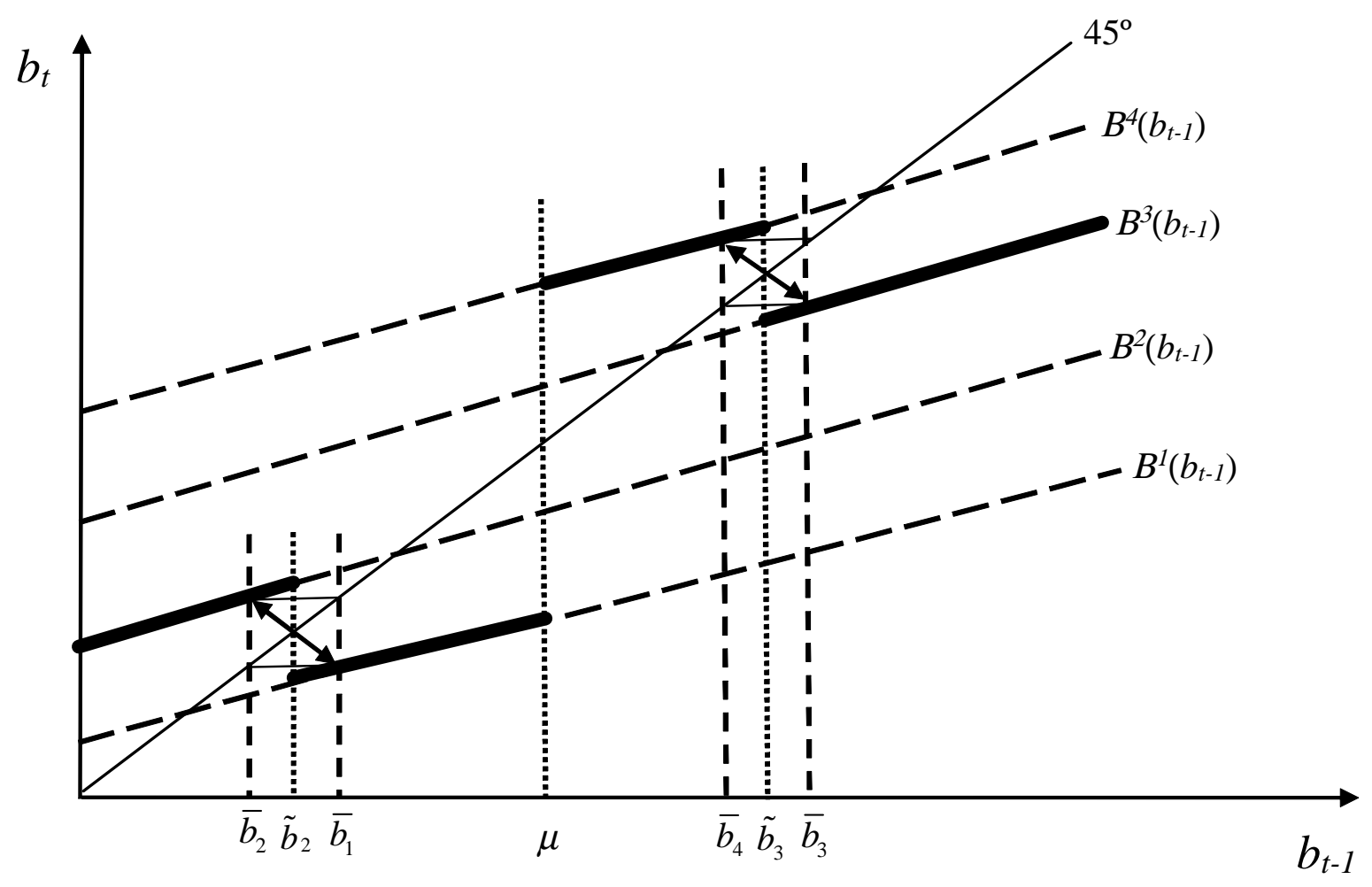

Figure 2. Cycles in the benchmark economy when $B^{3}>B^{2}$. 


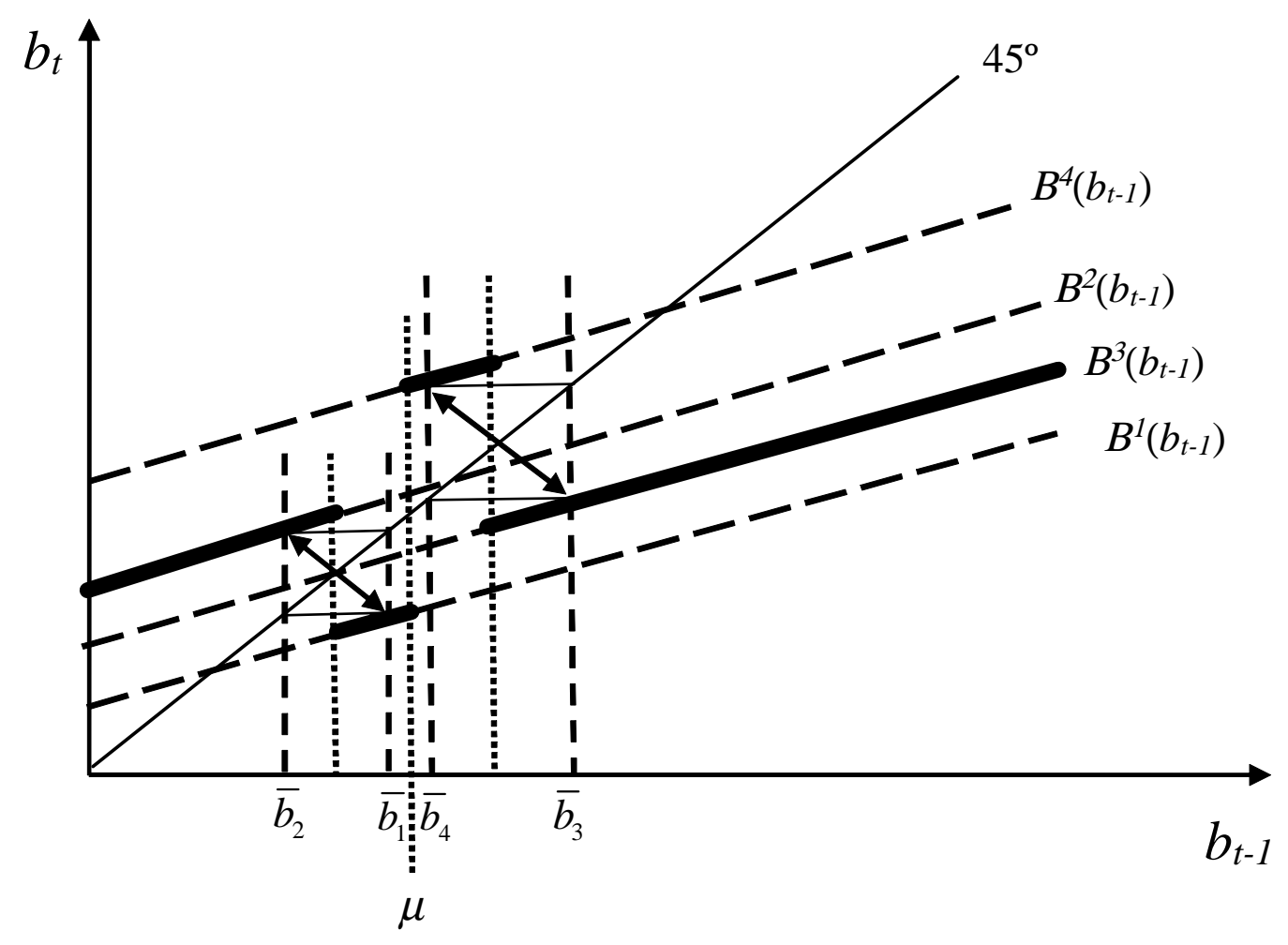

Figure 3. Cycles in the benchmark economy when $B^{2}>B^{3}$. 


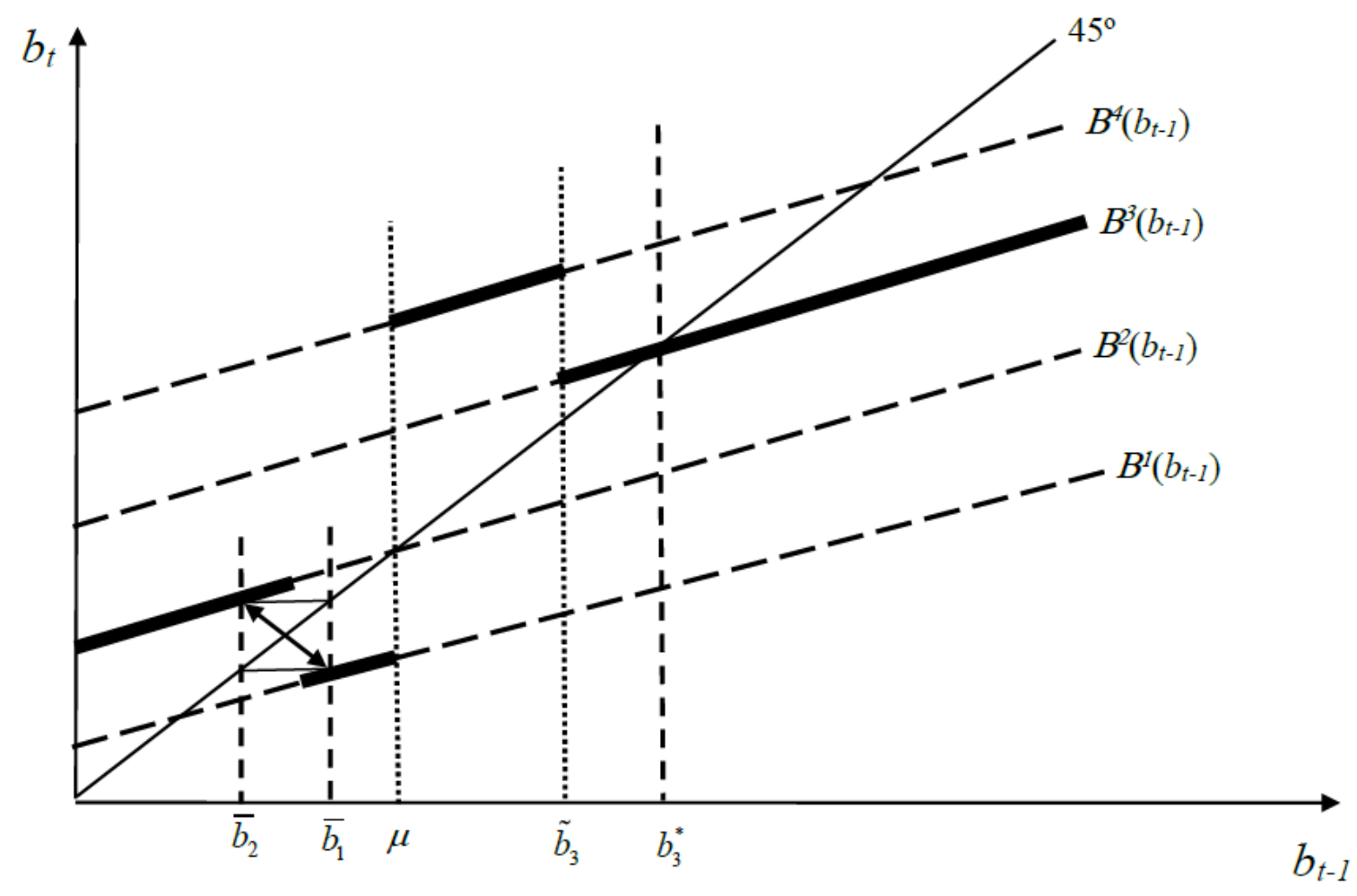

Figure 4. Equilibria after a big reduction in the cost $\mu$ of education. 


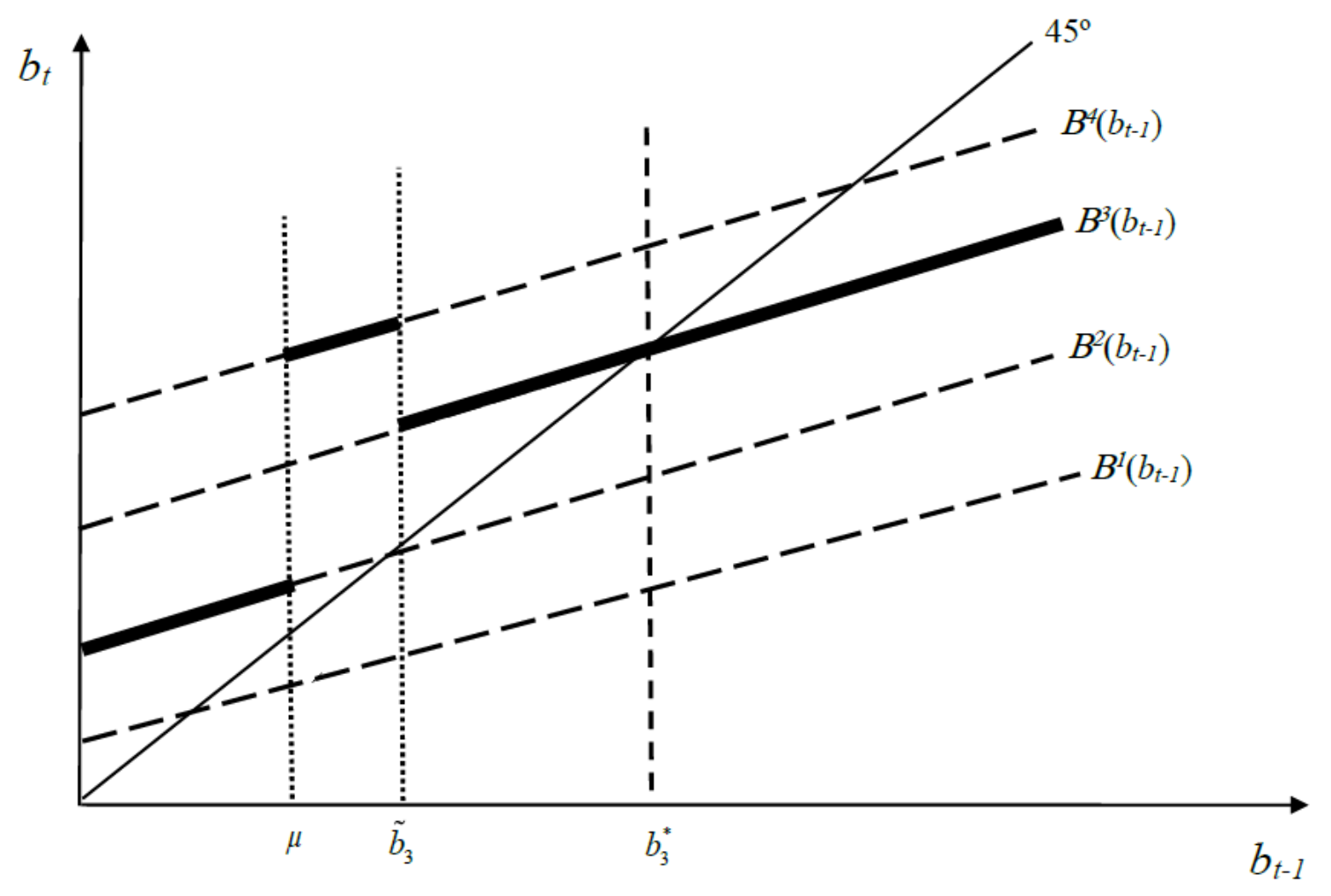

Figure 5. Equilibria after a very big reduction in the cost $\mu$ of education. 


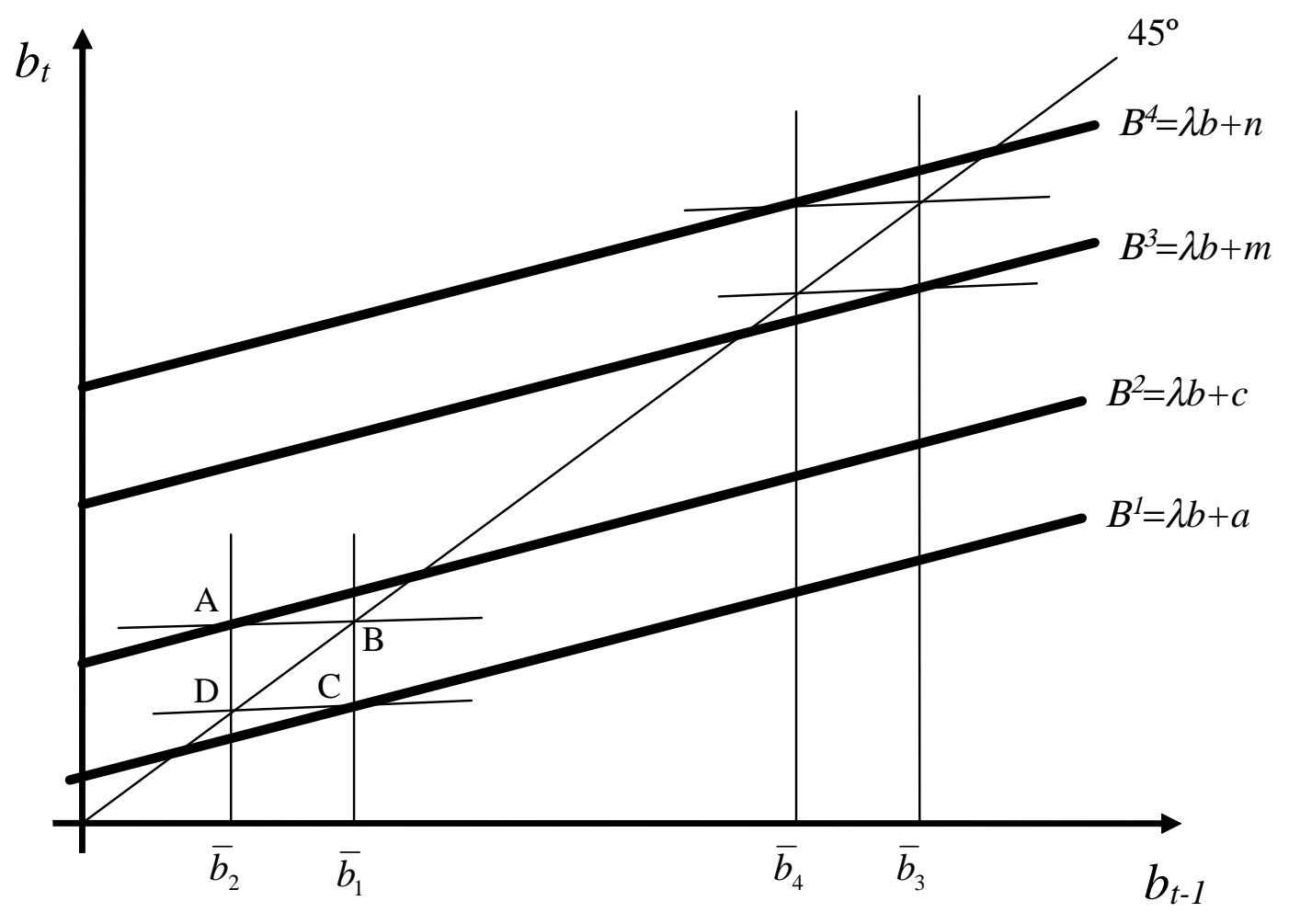

Figure 6. Characterization of cycles. 